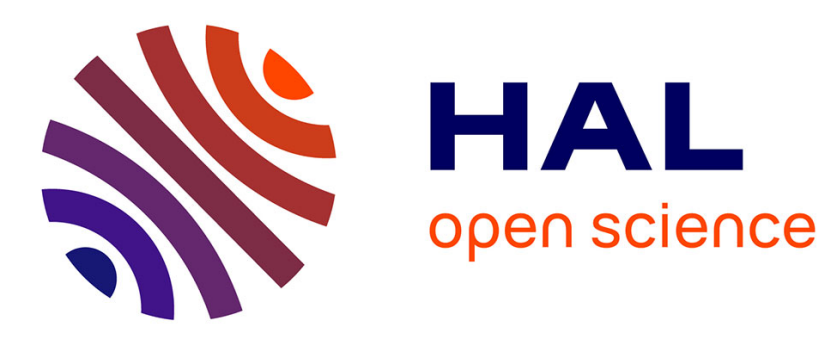

\title{
Effect of Cloud Cover on Temporal Upscaling of Instantaneous Evapotranspiration
}

Yazhen Jiang, Xiao-Guang Jiang, Ronglin Tang, Zhao-Liang Li, Yuze Zhang, Zhao-Xia Liu, Cheng Huang

\section{- To cite this version:}

Yazhen Jiang, Xiao-Guang Jiang, Ronglin Tang, Zhao-Liang Li, Yuze Zhang, et al.. Effect of Cloud Cover on Temporal Upscaling of Instantaneous Evapotranspiration. Journal of Hydrologic Engineering, 2018, 23 (4), pp.05018002. 10.1061/(ASCE)HE.1943-5584.0001635 . hal-02377711

\section{HAL Id: hal-02377711 \\ https://hal.science/hal-02377711}

Submitted on 8 Dec 2020

HAL is a multi-disciplinary open access archive for the deposit and dissemination of scientific research documents, whether they are published or not. The documents may come from teaching and research institutions in France or abroad, or from public or private research centers.
L'archive ouverte pluridisciplinaire HAL, est destinée au dépôt et à la diffusion de documents scientifiques de niveau recherche, publiés ou non, émanant des établissements d'enseignement et de recherche français ou étrangers, des laboratoires publics ou privés. 


\section{Effect of Cloud Cover on Temporal Upscaling of}

\section{Instantaneous Evapotranspiration}

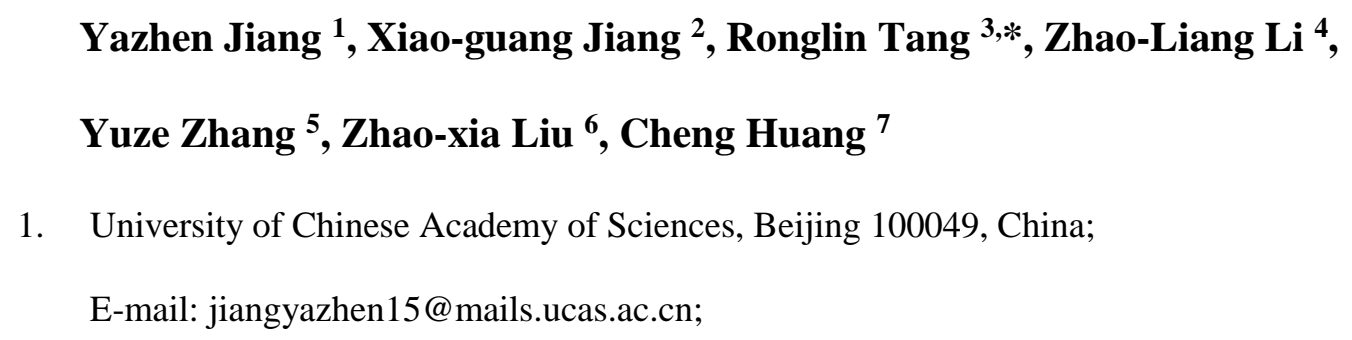

1. University of Chinese Academy of Sciences, Beijing 100049, China; E-mail: jiangyazhen15@mails.ucas.ac.cn;

2. University of Chinese Academy of Sciences, Beijing 100049, China; State Key Laboratory of Resources and Environmental Information System Institute of Geographic Sciences and Natural Resources Research, Chinese Academy of Sciences, Beijing 100101, China; Key Laboratory of Quantitative Remote Sensing Information Technology, Academy of Opto-Electronics, Chinese Academy of Sciences, Beijing 100094, China.

3. State Key Laboratory of Resources and Environmental Information System Institute of Geographic Sciences and Natural Resources Research, Chinese Academy of Sciences, Beijing 100101, China; University of Chinese Academy of Sciences, Beijing 100049, China.

4. Key Laboratory of Agri-informatics, Ministry of Agriculture/Institute of Agricultural Resources and Regional Planning, Chinese Academy of Agricultural Sciences, Beijing 100081, China; Icube (UMR7357), UdS, CNRS, 300 Bld Sébastien Brant, CS10413, Illkirch 67412, France.

5. University of Chinese Academy of Sciences, Beijing 100049, China.

6. Xinjiang Institute of Ecology and Geography, Chinese Academy of Sciences, Urumchi 830011, Xinjiang, China.

7. University of Chinese Academy of Sciences, Beijing 100049, China. 
Abstract: Studying the effect of cloud cover on temporal upscaling of instantaneous evapotranspiration (ET) is significant in efforts toward a more accurate and widely applied upscaling method to obtain exact ET at daily or longer time scale, thereby benefiting practical applications. In this article, the authors concentrated on the effects of cloud cover with different amounts and time durations on three commonly used upscaling approaches including the constant evaporative fraction (EF) method, the constant reference evaporative fraction $\left(\mathrm{EF}_{\mathrm{r}}\right)$ and the constant global solar radiation $\left(\mathrm{R}_{\mathrm{g}}\right)$ method. Transient cloud and persistent cloud were both defined according to occurrence time, namely, cloud appearance one hour before or after the upscaling moment and the cloud lasting the whole daytime except during upscaling time, respectively. Different cloud cover amounts were indicated by different losses of downwelling shortwave irradiance. Instantaneous fluxes were simulated from the Atmosphere-Land-Exchange (ALEX) model, which is driven by meteorology measurements at the Yucheng station. The results show that: (I) the cloud will deteriorate with the underestimation or overestimation of daily ET upscaling compared to the results of clear days. Specifically, persistent cloud had a more significant effect on the three upscaling methods; for transient cloud, the upscaling results had larger deviations when the cloud appeared before the upscaling moments than when it appeared after; (II) the effect on the upscaling factors and upscaling results both increased proportionally with the growth of cloud cover; (III) the constant $\mathrm{EF}_{\mathrm{r}}$ method performed best for both clear and cloudy situations with a minimal bias, less than $4.7 \mathrm{~W} / \mathrm{m}^{2}(5.5 \%)$ and an RMSE less than $8.9 \mathrm{~W} / \mathrm{m}^{2}(20.6 \%)$; the EF method was most severely affected with a bias up to $24.1 \mathrm{~W} / \mathrm{m}^{2}$ $(28.3 \%)$ and an RMSE up to $24.9 \mathrm{~W} / \mathrm{m}^{2}(57.7 \%)$; the $\mathrm{R}_{\mathrm{g}}$ method had intermediate accuracy with a bias less than $20.9 \mathrm{~W} / \mathrm{m}^{2}(24.6 \%)$ and an RMSE less than $20.3 \mathrm{~W} / \mathrm{m}^{2}(47.1 \%)$; (IV) all three approaches were influenced more significantly near noontime. 


\section{Introduction}

Evapotranspiration (ET) can be used effectively to express vegetation water consumption and surface moisture. Routine monitoring of actual ET is widely considered a significant scientific issue benefiting practical applications in a variety of fields, including water management, water rights regulation, drought monitoring and the study of climate change (Li et al., 2009; Tang et al., 2011; Cammalleri et al., 2014). Remote-sensing based approaches can be used to estimate the spatial distribution of ET at the regional or basin scale when satellite data are available (Courault et al., 2005), overcoming the problem related to conventional methods that they are being applied only at the site or field scale. However, current remote-sensing based ET models generally only provide snapshots of ET at the time of satellite overpass (Gómez et al., 2005; Colaizzi et al., 2006. Chávez et al., 2008), and ET integration over a longer time scale (days, months to years) is more important among many applications. Therefore, the instantaneous ET values at satellite overpass time must be upscaled temporally to make more sense.

Various ET temporal upscaling methods have been developed by assuming self-preservation of the ratio between ET and a given reference variable over the daytime hours (Crago, 1996; Bastiaanssen, 2000; Delogu et al., 2012). The constant evaporative fraction (EF) method is one of the most commonly used upscaling approaches, which assumes that EF (the ratio of latent heat flux to available energy) is constant during the daytime (Shuttleworth, 1989). Daily ET in this method can be obtained with daily available energy (difference of net radiation and soil heat flux) and remotely sensed instantaneous EF. A variety of studies have demonstrated the constancy of EF and its effectiveness in upscaling instantaneous ET from remote sensing data in clear skies (Nichols and Cuenca, 1993; Gentine et al., 2007). In the application of this method, the daytime ET is usually 
underestimated by 5\%-10\% (Brutsaert and Sugita, 1992; Chávez et al., 2008), which is partly due to the EF curve usually exhibiting a concave shape under wet conditions and the instantaneous EF near the noon is lower than the daily averaged value (Lhomme \& Elguero, 1999; Hoedjes et al., 2008). The underestimation is corrected by directly adding $10 \%$ ET in some studies (Anderson et al., 1997). Despite the controversies raised regarding its validity, the EF conservation method has been widely applied (Gómez et al., 2005; Galleguillos et al., 2011; Delogu et al., 2012).

Trezza (2002) introduced another ET upscaling method using standardized reference evapotranspiration $\left(\mathrm{ET}_{\mathrm{r}}\right)$ as the variable that depicts the diurnal variations of net radiation, air temperature, wind speed and relative humidity. This method is the so-called constant reference evaporative fraction $\left(\mathrm{EF}_{\mathrm{r}}\right.$, the ratio of actual $\mathrm{ET}$ to $\mathrm{ET}_{\mathrm{r}}$ ) method (Allen et al., 1998; 2006). The $\mathrm{EF}_{\mathrm{r}}$ is assumed to be constant during the daytime, and daily $\mathrm{ET}$ can be estimated through the ratio, together with daily $\mathrm{ET}_{\mathrm{r}}$. In this upscaling method, a fixed surface resistance is usually used for the calculation of $\mathrm{ET}_{\mathrm{r}}$. Tang et al. (2017 a) have investigated the application of variable surface resistances from the Penman-Monteith (PM) equation and found the accuracy could be improved only in some upscaling moments. Previous studies have stated that maintaining the conservation of $\mathrm{EF}_{\mathrm{r}}$ in a diurnal cycle could provide better estimates of daily ET under advective conditions (Trezza, 2002; Allen et al., 2007).

Other widely employed upscaling methods assume that the ratios between latent heat flux and other variables (e.g., solar radiation, solar radiation irradiance) are constant during the daytime, during which the variables are generally the primary energy drivers of surface water and energy transfer. For instance, latent heat flux and solar radiation are reported to have similar diurnal variations (e.g., sine functions), and the method mentioned is the constant global solar radiation $\left(\mathrm{R}_{\mathrm{g}}\right)$ method. Daily ET values have already been estimated with this relationship (Zhang and Lemeur, 1995; Ryu et al., 2012; Niel et al., 2011). Ryu et al. 
(2012) adopted the constant $\mathrm{R}_{\mathrm{g}}$ method to upscale the remotely sensed ET to daily and eight-day averaged values and showed it was a robust scaling method.

It appears that almost all of these upscaling methods can be effectively used to acquire daily ET over clear-sky days (Brutsaert and Sugita, 1992; Colaizzi et al., 2006; Ryu et al., 2012). The issue that arises is that cloud coverage is a prominent phenomenon in many parts of the world, and the mean cloud cover per day may even exceed $60 \%$ in the humid tropics (Bussieres and Goita, 1997). Cloud covers usually cause reductions in solar radiance and available energy, and thus affect diurnal changes in ET. Different occurrence times, coverage amounts and durations of cloud will have markedly different effects on ET variation, which will further influence applications of these upscaling methods that assume some self-preservative ratios between ET and other variables (Suigita and Brutsaert, 1991; Zhang and Lemeur, 1995; Crago, 1996). Jackson (1983) noted that the amount and duration of cloud cover during the daytime will affect the accuracy of upscaling methods. Niel and Mcvicar (2012) also indicated that the assumption of clear sky conditions during the whole day is not always assured for remote sensing applications, and it is feasible that only the specific time of the satellite overpass must be clear. To the best of our knowledge, the studies of these method as they relate to the effective assessment of cloud coverage are very rare, and ET was obtained in some applications from satellite images for a succession of clear days and interpolating the ratios for cloudy ones (Carlson et al., 1995; Xu et al., 2015). The presence of clouds is linked to a decrease in irradiance at the surface, and the cloudy days indicated by irradiance reduction have been validated as heavily overcast days using measurements. In Long's study (2000; 2006), cloud was defined as the difference between the measured downwelling irradiance and that expected for clear-sky conditions. Therefore, an elaborate understanding of the cloud cover effect on upscaling procedures is imperative and feasible. 
The objective of this paper is to comprehensively evaluate the cloud effect with different occurrence times, coverage amounts and duration times on these three temporal upscaling methods to explore an upscaling approach that can effectively consider the cloud effect and obtain exact daily ET. Instantaneous ET are simulated from the Atmosphere-Land-Exchange (ALEX) model. Transient cloud (cloud occurred one hour before or after the upscaling time, respectively) and persistent cloud (cloud lasted for almost the whole daytime except the upscaling time) were defined according to diverse appearance and duration time. Different cloud cover amounts were represented by the reduction of downwelling short wave irradiance of clear skies. The ratios between the ET and other variables, regarded as upscaling factors, are all assumed to be self-preservative in these three upscaling methods. The specific work of this current paper is to: (i) estimate the effect of different clouds on upscaling factors, (ii) estimate the effect of different clouds on upscaling results obtained through different upscaling methods compared to that of clear days, and (iii) find upscaling methods that have stable performances even under cloudy conditions.

\section{Study area and data}

\subsection{Study area}

This study was carried out at Yucheng station $\left(36.8291^{\circ} \mathrm{N}, 116.5703^{\circ} \mathrm{E}\right.$ ), which is in southwestern of Yucheng County, Shandong Province, in North China (Figure 1). The Yucheng station is part of the Chinese terrestrial ecosystem flux network, which aims to measure the long-term exchange of carbon dioxide, water vapor, and heat between the land and the atmosphere. The climate is subhumid and monsoonal, with a mean annual temperature of $13.1^{\circ} \mathrm{C}$ and precipitation of $528 \mathrm{~mm}$. The soil is sandy loam, and the land cover types near the station primarily consist of crop (winter-wheat and summer-corn rotation), bare soil, trees and water. 


\subsection{Study data}

The measurements from Yucheng station used in this study contain meteorological variables, radiation data, flux data and MODIS data for the period from late April 2009 to late October 2010. This period covers two phenological stages from emergence to close-to-peak biomass in winter wheat and summer corn. Meteorological variables, including air temperature, wind speed, relative humidity and atmospheric pressure, were measured at the height of $2.93 \mathrm{~m}$ during the growth period of wheat and at $4.2 \mathrm{~m}$ during the growth period of corn. Radiation data, including downwelling and upwelling shortwave and longwave radiations, were acquired from a CNR-1 radiometer installed at the height of $3.98 \mathrm{~m}$. The sensible heat flux (H) and latent heat flux (LE) were measured by an Eddy Covariance (EC) system consisting of an open-path $\mathrm{CO}_{2} / \mathrm{H}_{2} \mathrm{O}$ gas analyzer and a 3-D sonic anemometer/thermometer. The height of the EC facility was $2.7 \mathrm{~m}$ and $3.75 \mathrm{~m}$ during the growth period of wheat and corn, respectively. Soil heat flux $(\mathrm{G})$ was estimated from a single HFP-01 soil heat flux plate at $2 \mathrm{~cm}$ below the surface without considering heat transfer for the $2 \mathrm{~cm}$ storage layer above the plate. MODIS cloud quality control product (MOD35) was downloaded from the Atmosphere Archive and Distribution System Web (https://ladsweb.nascom.nasa.gov/data/search.html).

All the meteorological variables and the EC measurements were made in an experimental area with dimensions of approximately $250 \mathrm{~m}$ by $90 \mathrm{~m}$ at Yucheng station. The crop type of the experimental area is relatively uniform during the measuring periods. All data are recorded as a 30-min average, and there are 48 records in a day for each variable. Meteorological variables averaged every half hour and radiation data were collected as input data to drive the ALEX model. The in situ fluxes are used to validate the simulated results. It is noted that five-minute averaged data of downwelling shortwave radiations and MOD35 are also obtained for clear sky identification. 


\section{Methodology}

173

174

175

176

177

\subsection{ET upscaling method}

In this study, as described above, the upscaling methodologies for extrapolating instantaneous ET to daily value tested were the EF method, the $\mathrm{EF}_{\mathrm{r}}$ method and the $\mathrm{R}_{\mathrm{g}}$ method, respectively. Three upscaling methods were performed to estimate the actual daily ET from a single time-of-day snapshot, by assuming conservation of some ET factors over the course of the day. These factors are generally expressed as ratios between instantaneous ET at a specific time and a reference variable that can be computed hourly.

In the EF method, the $\mathrm{EF}$ factor was the ratio of latent heat flux (LE, used interchangeably with ET in this paper) to surface available energy (surface net radiation minus soil heat flux), expressed as

$$
E F_{i(d)}=\frac{L E_{i(d)}}{\left(R_{n}-G\right)_{i(d)}}
$$

The subscripts "i" and " $\mathrm{d}$ " represent the instantaneous and daily averaged values, respectively. The daily $L E$ can be estimated once the daily integrated net radiation $R_{n}$ and the instantaneous EF at the satellite overpass time are derived (Daily $\mathrm{G}$ is assumed to zero (Tang al., 2013) due to the balance of daytime $G$ and nighttime $G$ to reduce the estimation error of G). Thus, daily LE can be obtained by

$$
L E_{d}=E F_{i}\left(R_{n}\right)_{d}
$$

Similarly, in the $\mathrm{EF}_{\mathrm{r}}$ method, the factor $\mathrm{EF}_{\mathrm{r}}$ is the ratio of latent heat flux (LE) to reference evapotranspiration $\left(\mathrm{ET}_{\mathrm{r}}\right)$ expressed as

$$
E F r_{i(d)}=\frac{L E_{i(d)}}{\operatorname{ETr}_{i(d)}}
$$

and daily LE in this method was calculated by

$$
L E_{d}=E F r_{i}(E T r)_{d}
$$


In addition, the reference evapotranspiration $\left(\mathrm{ET}_{\mathrm{r}}\right)$ in this method is estimated from the Penman-Monteith equation as suggested by ASCE-EWRI (2005), which is for a hypothetical grass with an assumed height of $0.12 \mathrm{~m}$ having a surface resistance of $50 \mathrm{~s} / \mathrm{m}$ during the daytime and $200 \mathrm{~s} / \mathrm{m}$ during nighttime and an albedo of 0.23 . The expression is

$$
E T r=\frac{0.408 \Delta\left(R_{n}-G\right)+\gamma \frac{C_{n}}{T_{a}+273} u_{2}\left(e_{s}-e_{a}\right)}{\Delta+\gamma\left(1+C_{d} u_{2}\right)}
$$

where $\Delta$ is the slope of the saturated vapor pressure vs. air temperature curve, $\mathrm{kPa} /{ }^{\circ} \mathrm{C} ; \mathrm{R}_{\mathrm{n}}$ is the surface net radiation, $\mathrm{W} / \mathrm{m}^{2} ; \mathrm{G}$ is the soil heat flux, and daily $\mathrm{G}$ is assumed to be zero, $\mathrm{W} / \mathrm{m}^{2} ; \quad \gamma$ is the psychrometric constant, $\mathrm{kPa} /{ }^{\circ} \mathrm{C} ; \mathrm{C}_{\mathrm{n}}$ equals 900 on a daily scale and equals 37 on an hourly scale; $\mathrm{T}_{\mathrm{a}}$ is the air temperature, ${ }^{\circ} \mathrm{C} ; \mathrm{e}_{\mathrm{s}}-\mathrm{e}_{\mathrm{a}}$, is the vapor pressure deficit, $\mathrm{kPa} ; \mathrm{u}_{2}$ is the wind speed at $2 \mathrm{~m}$ height, $\mathrm{m} / \mathrm{s} ; \mathrm{C}_{\mathrm{d}}$ equals 0.24 during the daytime and 0.96 during nighttime.

In the $\mathrm{R}_{\mathrm{g}}$ method, the factor $\mathrm{R}_{\mathrm{g}}$ was the ratio of latent heat flux (LE) to global solar radiation $\left(\mathrm{R}_{\mathrm{s}}\right)$.

\subsection{Atmosphere Land Exchange (ALEX) model}

$$
R_{g(i, d)}=\frac{L E_{(i, d)}}{R_{s(i, d)}}
$$

and daily LE will be acquired from

$$
L E_{d}=R_{g i}\left(R_{s}\right)_{d}
$$

All the instantaneous flux data in this study including latent heat flux (LE), sensible heat flux $(H)$, net radiation $\left(R_{n}\right)$, and soil heat flux $(G)$ are simulated from the Atmosphere-Land Exchange (ALEX) model. The ALEX is a two-layer (soil and vegetation) model of heat, water and carbon exchange between a vegetated surface and the atmosphere. 
In the ALEX model, the LE at the measurement reference height represents water vapor evaporation from the insides of leaf stomas $\left(\mathrm{LE}_{\mathrm{c}}\right)$ and the soil surface $\left(\mathrm{LE}_{\mathrm{s}}\right)$. Sensible heat $(\mathrm{H})$ is transferred from the canopy air space due to sensible heat convection or conduction from leaf $\left(\mathrm{H}_{\mathrm{c}}\right)$ and soil surface $\left(\mathrm{H}_{\mathrm{s}}\right)$. The net ecosystem $\mathrm{CO}_{2}$ exchange incorporates the assimilation of $\mathrm{CO}_{2}$ inside plant leaves through the stomas minus leaf respiration $\left(\mathrm{A}_{\mathrm{c}}\right)$ and respiratory loss of $\mathrm{CO}_{2}$ from soil and roots $\left(\mathrm{A}_{\mathrm{s}}\right)$. These fluxes are regulated by series-parallel resistance networks that allow both soil and canopy components of the system to modify the in-canopy air temperature and vapor pressure (Houborg et al., 2009). The model generates transpiration and carbon assimilation fluxes that agree well with estimates from iterative mechanistic photosynthetic models and coincide with flux measurements in various kinds of vegetation as well. The robustness of the model over a variety of vegetative and climatic regimes was demonstrated in various applications (Lu et al., 2013), suggesting that this simple analytical model of canopy resistance will be useful in regional-scale flux estimations. Details of the model can be found in Anderson's study (Anderson et al., 2000).

The ALEX model is computationally efficient and requires few species-specific parameters. Atmosphere forcing data, soil properties and vegetation characteristics are required as inputs to the model. In this study, 30-min averaged meteorological variables including air temperature, vapor pressure, wind speed, relative humidity, atmospheric pressure and solar radiation data were collected to drive the model, together with soil and vegetation characteristic data, which are shown in table 1. 


\subsection{Experiment design}

\subsubsection{Clear sky identification}

Clear days were selected first for comparison in this study, using the procedure presented by Long (2000). In Long's method, the measurements of surface total downwelling and diffuse shortwave irradiance were used to precisely identify the 1-minute clear sky moments, where total downwelling short wave irradiance is the main element for clear sky identification and the latter is applied as a supplement to match the typical climatological location. In this study, five-minute downwelling shortwave irradiance was used only to select clear sky days, due to our finite measurements and the low requirement of half-hour time scale for matching other data.

Based on the incoming downwelling shortwave radiation, clear sky days at Yucheng station were selected from late April of 2009 to late October of 2010. The identification results of clear days were further guaranteed by MODIS cloud quality control data, MOD35. For the MOD35 data, the quality assurance (QA) flags in binary varied from 00 to 11 and only 11 (highest quality) were selected, according to which the invalid data were eliminated. Finally, 21 cloud-free days were obtained, and the day of year (DOY) for each is shown in table 2 .

\subsubsection{Cloud definition}

After selecting completely clear days, different hourly time intervals were picked out from mid-morning (9:00 local time) to mid-afternoon (15:00 local time) for each clear day to be assumed as the satellite overpass time and to be taken as the upscaling time.

Then two main types of cloud were defined:

(1) Transient cloud. Two kinds of transient cloud were used, according to different occurrence times that include one hour before upscaling time and one hour after upscaling 
time. Correspondingly, downwelling shortwave irradiances were reduced, and the reductions were set to $100 \mathrm{~W} / \mathrm{m}^{2}, 200 \mathrm{~W} / \mathrm{m}^{2}$ and $300 \mathrm{~W} / \mathrm{m}^{2}$ to indicate different amounts of cloud cover, respectively (Long et al., 2000; 2006).

(2) Persistent cloud. Persistent cloud was defined by subtracting shortwave irradiance from 8:00 to 17:00, except for upscaling moments of every clear day. To show different cloud cover amounts, the reductions were set to $100 \mathrm{~W} / \mathrm{m}^{2}, 200 \mathrm{~W} / \mathrm{m}^{2}$ and $300 \mathrm{~W} / \mathrm{m}^{2}$ as well. Whether a transient cloud or persistent cloud occurred, upscaling moments were all kept clear. The occurrence time of different clouds is displayed in detail in table 3.

After clouds were defined, half-hour fluxes including $L E, H, R_{n}$ and $G$ were simulated by the ALEX model in the conditions of clear, transient-cloud and persistent-cloud days, respectively. In the simulations, the inputs of the ALEX model were shortwave irradiances in three different situations together with other meteorology data, which were unchanged in all situations for the same DOY. Fluxes simulated on clear days were validated by comparing them to corresponding in situ measurements.

Based on these fluxes, the authors assessed the performances of three upscaling methods mentioned above in upscaling instantaneous LE to daily (24-h) LE at different upscaling times when different clouds occurred. During the assessments of the EF method, the required daily $R_{n}$ was derived by averaging the half-hour data simulated from the ALEX model over a 24-h period. For the $\mathrm{EF}_{\mathrm{r}}$ method, daily $\mathrm{ET}_{\mathrm{r}}$ was also acquired by averaging the half-hour $\mathrm{ET}_{\mathrm{r}}$ which was calculated using a combination of meteorology data from the ground-based measurements and modeled $R_{n}$ and $G$. For the $R_{g}$ method, daily $R_{s}$ was totally computed from averaging half-hour in situ measurements in clear days and from measurements after the reductions according to different cloud types on cloudy days. 


\section{Results and Discussion}

\subsection{Upscaling results on clear days}

\subsubsection{Fluxes simulated from the ALEX on clear days}

For the 21 selected clear days, half-hour latent heat flux (LE), sensible heat flux $(\mathrm{H})$, net radiation $\left(R_{n}\right)$, and soil heat flux $(G)$ simulated from the ALEX model were compared with corresponding in situ measurements (Figure 2). It is apparent that the simulated LE (Figure 2a) and $R_{n}$ (Figure 2c) agreed with the measured values, and both were slightly underestimated. Specifically, the bias (simulated data minus in situ data) and root mean square error (RMSE) of the LE simulation were $13.95 \mathrm{~W} / \mathrm{m}^{2}$ and $49.01 \mathrm{~W} / \mathrm{m}^{2}$, respectively, with a coefficient of determination $\left(\mathrm{R}^{2}\right)$ of 0.895 . The bias and RMSE of the $\mathrm{R}_{n}$ simulation were $35.90 \mathrm{~W} / \mathrm{m}^{2}$ and $57.0 \mathrm{~W} / \mathrm{m}^{2}$, respectively, with an $\mathrm{R}^{2}$ of 0.978 . Regarding the $\mathrm{H}$ (Figure.2b) and $\mathrm{G}$ (Figure.2d) simulations, there existed large discrepancies between the simulated data and measured data. The value of $\mathrm{H}$ was underestimated by an average bias of 64.32 W/m² with an RMSE of $78.03 \mathrm{~W} / \mathrm{m}^{2}$ and an $\mathrm{R}^{2}$ of 0.730 . The value of $\mathrm{G}$ was overestimated by a bias of $80.38 \mathrm{~W} / \mathrm{m}^{2}$ with an RMSE of $109.75 \mathrm{~W} / \mathrm{m}^{2}$ and an $\mathrm{R}^{2}$ of 0.465 .

It is shown that the ALEX model had significantly different performances in simulating the different fluxes in this study. The large differences between simulated and measured $\mathrm{H}$ and $\mathrm{G}$ were mainly assumed to be from the energy imbalance and the mismatches between the soil moisture measured from three-layer soils and that needed in the ALEX model as input which was divided into 12 layers (Lu et al., 2014). The energy closure rate (the ratio between the $(\mathrm{LE}+\mathrm{H})$ to the $\left(\mathrm{R}_{\mathrm{n}}-\mathrm{G}\right)$, used to indicate the degree of energy balance) of in situ measurements is nearly 0.57 , while that of the simulated fluxes is approximately 0.98 . The reasons for the energy imbalance of in situ fluxes are usually from the measurement error, the length of the sampling intervals, the dispersive fluxes not being 
sampled by the EC system and the neglect of heat storage for photosynthesis. Different considerations of these elements in the simulation procedure may generate differences between in situ and simulated fluxes. For the soil moisture, it affects the temperature of surface which determines the loss of $\mathrm{H}$ from surface and affects $\mathrm{G}$.

It should be noted that $\mathrm{H}$ is not adopted in the following process judging from Eq. (1)-(7), which is used only for the analysis of the reason for simulation discrepancy from the view of energy imbalance. For the detailed effect of the simulated deviation from $\mathrm{G}$ on the three upscaling factors, it will slightly affect the instantaneous EF only. In the formula for EF, the instantaneous $\mathrm{LE}$ and $\mathrm{R}_{\mathrm{n}}$ simulated are more consistent with the measured data and $\mathrm{G}$ usually accounts for a small proportion of $\mathrm{R}_{\mathrm{n}}$ (Teixeira et al.,2009). The other two factors, $\mathrm{EF}_{\mathrm{r}}$ and $\mathrm{R}_{\mathrm{g}}$ which primarily depend on well simulated instantaneous LE, measured meteorological characteristics and global solar radiations, are unaffected by the simulation discrepancy of G. For the influence of simulation discrepancy on daily LE acquisition, it is mainly related to the effect of these upscaling factors because daily $R_{n}, E_{r}$ and $R_{s}$ in daily $L E$ calculations have little to do with simulated G.

The $\mathrm{G}$ fluxes in cloudy situations can only be acquired by simulation. If a simulated value of $\mathrm{G}$ from a clear day was taken place, the estimation errors in cloudy days will be imponderable. Moreover, this study was focused on the relative change of upscaling results between clear and cloudy conditions, which is also the important part of our schemes for cloud effect evaluation. Therefore, it is feasible to use the fluxes (LE, $R_{n}$ and G) simulated from the ALEX model and regard them as the true value to evaluate the effect of cloud on different extrapolation methods in diverse situations.

\subsubsection{Variations of upscaling factors on clear days}

Before evaluating the performances of three upscaling methods in extrapolating instantaneous LE to daily values, the variations of three upscaling factors including $\mathrm{EF}, \mathrm{EF}_{\mathrm{r}}$ 
and $\mathrm{R}_{\mathrm{g}}$ in clear days were examined (Figure 3 ). All these factors were half-hour averages taken over 21 selected clear-sky days from 09:00 to 15:00 local time.

Figure 3 indicates that three upscaling factors $\left(\mathrm{EF}, \mathrm{EF}_{\mathrm{r}}\right.$ and $\left.\mathrm{R}_{\mathrm{g}}\right)$ were shown as smooth curves during the period of 9:00 $\mathrm{h}$ to 15:00 $\mathrm{h}$. The standard deviation of the $\mathrm{EF}, \mathrm{EF}_{\mathrm{r}}$ and $\mathrm{R}_{\mathrm{g}}$ factors were $0.077,0.036$, and 0.009 , respectively. The value of EF during the period varied from 0.8 to 1.04 and was larger in the early morning and late afternoon than at noon, thus there was a concavity in the EF curve which was also found in other studies (Rowntree, 1991). For the $\mathrm{EF}_{\mathrm{r}}$ factor, it varied less, and its value was approximately 0.85-1.0. Previous studies have stated that $\mathrm{EF}_{\mathrm{r}}$ could maintain the conservation better in a diurnal cycle and provide better estimates of the daily ET, even under advective conditions (Trezza, 2002; Allen et al, 2006). The $\mathrm{R}_{\mathrm{g}}$ factor varied from 0.2 to 0.3 , which was much smaller than the other two factors and had the least variation on clear days.

\subsubsection{Upscaling results on clear days}

The data reported in Figure 4 summarized statistical measures including bias, RMSE and $\mathrm{R}^{2}$ of the daily LE obtained following the three upscaling methodologies, showing all clear days on average at the different upscaling times. Specifically, positive bias means that the estimated daily LE is higher than the simulated value. Conversely, negative bias indicates an underestimation of the daily LE. Relative bias, which is the ratio of the bias to the mean, and relative RMSE, which is the ratio of the RMSE to the standard deviation of the data are also used to show the upscaling results of the three methods, following in brackets after the bias and RMSE.

In Figure 4, the lowest absolute bias and RMSE along with the largest $\mathrm{R}^{2}$ related to the $\mathrm{EF}_{\mathrm{r}}$ method distinctly demonstrated the highest accuracy at all acquisition times, which was in line with the study of Tang et al (2013). Daily LE obtained through the $\mathrm{EF}_{\mathrm{r}}$ method was slightly overestimated in the morning, with the bias of less than $1.1 \mathrm{~W} / \mathrm{m}^{2}(1.2 \%)$, and was 
underestimated in the afternoon, with bias of less than $1.7 \mathrm{~W} / \mathrm{m}^{2}(1.8 \%)$. The RMSE related to this method was less than $2 \mathrm{~W} / \mathrm{m}^{2}(4.4 \%)$, and the $\mathrm{R}^{2}$ was more than 0.986 . The other two upscaling methods both undervalued the daily LE on clear days. The underestimation related to the EF method is partly due to the EF curve near noon usually being lower than the daily averaged value (Lhomme \& Elguero, 1999; Hoedjes et al., 2008). The underestimation from the $\mathrm{R}_{\mathrm{g}}$ method was also found in another study (Brutsaert and Sugita, 1992), which reaches approximately $5-10 \%$ of the upscaling results. Daily LE associated with the EF method was undervalued by $0.15-6.39 \mathrm{~W} / \mathrm{m}^{2}(0.1-6.9 \%)$ with RMSEs of $4.70-8.43 \mathrm{~W} / \mathrm{m}^{2}(10.4-18.7 \%)$ and an $\mathrm{R}^{2}$ of more than 0.979 . The performance of the EF method changed within a wide range. Daily LE that resulted from the $\mathrm{R}_{\mathrm{g}}$ method had a smaller bias, of less than $3.5 \mathrm{~W} / \mathrm{m}^{2}$ (3.8\%), and the RMSEs were approximately 7.21-8.95 W/m² (16.0-19.8\%), with an $\mathrm{R}^{2}$ of more than 0.972. For a specific moment, the $\mathrm{EF}_{\mathrm{r}}$ method performed better in the morning and at noon. The EF method showed excellent results during the 9:00-10:00 interval, with an RMSE of $3.37 \mathrm{~W} / \mathrm{m}^{2}(7.5 \%)$ and an $\mathrm{R}^{2}$ of 0.986 . The $\mathrm{R}_{\mathrm{g}}$ method also had the best accuracies during the 9:00-10:00 interval, with an RMSE of 7.21 W/m² (16.0\%) and an $\mathrm{R}^{2}$ of 0.976.

By integrating the assessments of the upscaling results on clear days, it is obvious that all three methods performed well at all acquisition times. On the other hand, the decent behaviors of the three approaches during the extrapolation process in clear days also confirmed the feasibility of using modeled fluxes to evaluate cloud effects.

\subsection{The effect of transient cloud}

Two kinds of transient cloud were defined by different occurrence times, namely, cloud appeared one hour before or after upscaling time, respectively. These are discussed individually in the following. 
4.2.1 Variations of upscaling factors under transient-cloud condition

To accurately extrapolate instantaneous LE to a daily value, it is essential to find a conservative factor that is independent of the atmospheric variations and can be widely used. In transient-cloud situations, when the cloud appeared one hour before upscaling moments, three upscaling factors $\left(\mathrm{EF}, \mathrm{EF}_{\mathrm{r}}\right.$ and $\left.\mathrm{R}_{\mathrm{g}}\right)$ were affected. That is, because these factors were taken as the ratios of instantaneous LE to available energy $\left(R_{n}-G\right)$, reference evapotranspiration $\left(E T_{r}\right)$ and global solar radiation $\left(R_{s}\right)$, respectively, which were influenced by the preceding cloud. Obviously, when the transient cloud appeared after upscaling moments, these factors were not changed due to these unchanged items.

When the cloud appeared before the upscaling moments, the relative variations of three factors compared to that on clear days at a specific acquisition time were demonstrated in Figure 5. The EF factors increased and the variations were approximately $0.05,0.10$ and 0.15 when cloud amounts were $100 \mathrm{~W} / \mathrm{m}^{2}, 200 \mathrm{~W} / \mathrm{m}^{2}$ and $300 \mathrm{~W} / \mathrm{m}^{2}$, respectively. The conclusion that EF increases when the cloud occurs was also shown in some previous studies. For instance, in Crago's study (1996) it was considered that some complicated elements related to weather, soil moisture and biophysical conditions contribute to the variability of EF on individual days, but cloudiness and advection are the two dominating factors in determining the variation amount of EF. Sugita and Brutsaert (1991) also attributed changes of $\mathrm{EF}$ to cloudiness in the daytime progression. In contrast, the other two factors, $\mathrm{EF}_{\mathrm{r}}$ and $\mathrm{R}_{\mathrm{g}}$, both decreased in comparison to that of clear days. The $\mathrm{EF}_{\mathrm{r}}$ factor at a specific time is decided by the instantaneous $\mathrm{LE}$ and $\mathrm{ET}_{\mathrm{r}}$. The $\mathrm{ET}_{\mathrm{r}}$ was almost unchanged over a short time because it is strongly dependent on constant meteorological characteristics; thus, the decrease in the $\mathrm{EF}_{\mathrm{r}}$ factor was mainly due to the reduction of instantaneous LE caused by the transient cloud. Similarly, $\mathrm{R}_{\mathrm{g}}$ was also lower than that on clear days, resulting from a combination of unchanged instantaneous $R_{s}$ and the reduction of instantaneous LE. The 
absolute variations of $\mathrm{EF}, \mathrm{R}_{\mathrm{g}}$ and $\mathrm{EF}_{\mathrm{r}}$ were less than $0.02,0.012,0.011$, respectively, even when the cloud amount was $300 \mathrm{~W} / \mathrm{m}^{2}$. The largest variation occurred near noon, which may be caused by slightly more variation in the instantaneous LE.

\subsubsection{Upscaling results when transient cloud appeared before upscaling time}

When a transient cloud appeared before upscaling moments, the daily LE upscaled through the three upscaling methods at all acquisition times were shown in Figure 6. When compared with simulated daily LE for validation data, upscaled daily LE was displayed in Figure 6(d) for further analysis. It is declared that using the EF method and the $\mathrm{R}_{\mathrm{g}}$ method still resulted in underestimations of the daily $\mathrm{LE}$ and using the $\mathrm{EF}_{\mathrm{r}}$ method led to an overestimation. Extrapolated daily LE at the same acquisition time decreased with the cloud cover growth, shown by the graphic markers located from right to left, when cloud amounts ranged from $100 \mathrm{~W} / \mathrm{m}^{2}$ to $300 \mathrm{~W} / \mathrm{m}^{2}$. The phenomenon was coincident in all three method's application and was a further proof that the amount of cloud amount growth brings a reduction of extrapolated daily LE. In addition, simulated daily LE used as validations was also decreased compared to that of clear days and the reduction amount was also enlarged as the cloud cover increased (Figure 6(d)).

To further evaluate the transient-cloud effect, statistical bias, RMSE and $\mathrm{R}^{2}$ of upscaling results at a specific time were subsequently investigated (Figure 7). Increased biases revealed that the underestimation and overestimation of daily LE were more obvious compared to that of clear days. The absolute biases associated with the $\mathrm{EF}_{\mathrm{r}}, \mathrm{EF}$ and $\mathrm{R}_{\mathrm{g}}$ methods were approximately $0.5-3.8 \mathrm{~W} / \mathrm{m}^{2}(0.6-4.2 \%), 1.4-8.9 \mathrm{~W} / \mathrm{m}^{2}(1.5-9.7 \%)$ and $1.4-10 \mathrm{~W} / \mathrm{m}^{2}$ $(1.5-10.9 \%)$, respectively. Under this condition, although the EF factor increased, a larger reduction of daily net radiation $\left(\mathrm{R}_{\mathrm{n}}\right)$ resulted in a more significant underestimation of daily LE compared to that of clear days. The overvaluation resulted from the $\mathrm{EF}_{\mathrm{r}}$ method being relatively less changed, which was mainly due to a combination of the slightly decreased 
$\mathrm{EF}_{\mathrm{r}}$ factor and constant daily $\mathrm{ET}_{\mathrm{r}}$. For the $\mathrm{R}_{\mathrm{g}}$ method, both decreases of the $\mathrm{R}_{\mathrm{g}}$ factor and daily global solar radiation made the underestimation more obvious. The aggravated error was also exhibited by an increased RMSE. The RMSEs of daily LE from the $\mathrm{EF}_{\mathrm{r}}, \mathrm{EF}$ and $\mathrm{R}_{\mathrm{g}}$ method were approximately $6.1-8.5 \mathrm{~W} / \mathrm{m}^{2}(14.4-20.1 \%), 6.0-10.5 \mathrm{~W} / \mathrm{m}^{2}(14.1-24.7 \%)$ and 7.1-10.7 W/m $\mathrm{m}^{2}(16.7-25.2 \%)$, respectively. The $\mathrm{R}^{2}$, related to the $\mathrm{EF}_{\mathrm{r}}, \mathrm{EF}$ and $\mathrm{R}_{\mathrm{g}}$ methods decreased compared to that of clear days and was about $0.97-0.98,0.97-0.98$ and $0.96-0.98$, respectively. The biases and RMSEs of the daily LE through three methods increased with the growth of the cloud amount as well.

In this situation at Yucheng station, the $\mathrm{EF}_{\mathrm{r}}$ method still had the highest accuracy, and the $\mathrm{R}_{\mathrm{g}}$ and EF methods also showed similar behaviors, which were coincident with those of clear days. For a specific time, statistical biases and RSMEs resulted from these three methods were the largest with the least $\mathrm{R}^{2}$ when the upscaling moment was chosen to be 11:00-12:00 interval, showing more effects of transient cloud near noon.

\subsubsection{Upscaling results when transient cloud appeared after upscaling time}

When the transient-cloud appeared one hour after the upscaling time, the daily LE estimation had less errors (Figure 8). Similar to when the cloud appeared before upscaling moments, the daily LE extrapolated by the EF method and the $\mathrm{R}_{\mathrm{g}}$ method were both undervalued, and that of the $\mathrm{EF}_{\mathrm{r}}$ method was overestimated, but the estimates were apparently more accurate. Simulated daily LE displayed in Figure 8 (d) was also reduced compared to that of clear days, and the reduction was increased as the cloud cover increased. Different from when the cloud appeared before upscaling time, the reduction of simulated daily LE was narrowed in the later afternoon, while it narrowed in the early morning in the former situation. That is, simulated daily LE decreased less when the cloud appeared too early (before 9:00) or too late (after 15:00); in other words, it was also more influenced by the cloud at noon. 
Narrowed statistical bias, RMSE and an enhanced $\mathrm{R}^{2}$ of the daily LE at the specific time

461

462

463

464

465

466

467

468

469

470

471

472

473

474

475

476

477

478

479

480

481

482

483

further revealed superior performances of the three upscaling method when the cloud occurred after the upscaling time (Figure 9). The absolute biases of resulting from the $\mathrm{EF}_{\mathrm{r}}$, EF and $R_{g}$ methods were approximately $0.1-1.7 \mathrm{~W} / \mathrm{m}^{2}(0.1-1.8 \%), 1.3-8.1 \mathrm{~W} / \mathrm{m}^{2}(1.4-8.8 \%)$ and $0.8-4.5 \mathrm{~W} / \mathrm{m}^{2}(0.9-4.9 \%)$, respectively. The corresponding RMSEs were approximately 4.7-5.8 W/m 2 (11.0-13.7\%), 5.1-8.9 W/m² (12-20.9\%) and 5.2-8.1 W/m² $(12.3-19.1 \%)$, respectively, evidently lower than that of former transient-cloud condition. The $\mathrm{R}^{2}$ value of the daily LE upscaling were all larger at each upscaling moment.

Under this condition, all upscaling factors were not changed, and the statistical biases totally came from daily $R_{n}, E T_{r}$ and $R_{s}$ estimation, respectively. Specifically, upscaling bias regarding the $\mathrm{EF}_{\mathrm{r}}$ method resulted from the unchanged $\mathrm{EF}_{\mathrm{r}}$ factor and the slightly varied daily $\mathrm{ET}_{\mathrm{r}}$. For the EF method, the upscaling bias was slightly less than that of former cloudy situation, in which the EF factor increased and the $\mathrm{R}_{\mathrm{n}}$ decreased more severely. Similarly, the less absolute bias of the $\mathrm{R}_{\mathrm{g}}$ method was rooted in the unchanged $\mathrm{R}_{\mathrm{g}}$ factor and decreased daily $\mathbf{R}_{\mathrm{s}}$

It is deemed that three upscaling methods all performed better when the transient cloud appeared after the upscaling moments than before, and more serious variations of upscaling factors will lead to much more upscaling error.

\subsection{The effect of persistent cloud}

Persistent cloud was defined by a reduction of the shortwave irradiance from 8:00-17:00 except for the upscaling hour, and different amounts of cloud cover were also shown by the loss of $100 \mathrm{~W} / \mathrm{m}^{2}, 200 \mathrm{~W} / \mathrm{m}^{2}$ and $300 \mathrm{~W} / \mathrm{m}^{2}$, respectively. The effects of the persistent cloud on the upscaling factors and results were discussed. 
4.3.1 Variations of factors under the persistent-cloud condition

Significant variations in the three upscaling factors can be seen in the persistent-cloud situation in Figure 10. Compared to the transient-cloud situation, the variations of the three factors were noticeably larger. The EF increased sharply, and the variation even reached nearly 0.04 , when the cloud amount was $300 \mathrm{~W} / \mathrm{m}^{2}$. The $\mathrm{R}_{\mathrm{g}}$ factor decreased and the greatest variation even exceeded 0.03 . The $\mathrm{EF}_{\mathrm{r}}$ factor also decreased, but the variation was still small and less than 0.025 . The variation of the same factor also increased proportionally as the cloud amounts increased.

Under this situation, the cloud lasted almost the whole daytime, from 8:00 h to 17:00 h, except the upscaling moment, and cloud duration time before the specific upscaling moment differed. The later the upscaling time, the longer the duration of time in which the cloud lasted before upscaling. It is shown in Figure 10 that when the upscaling time was chosen to be the late afternoon, three factors exhibited the largest variations, directly related to the longest cloud duration.

\subsubsection{Upscaling results under the persistent-cloud condition}

The expanded deviation of the daily LE estimation notably demonstrated the serious effect of persistent cloud on three upscaling methods, shown in Figure 11, compared to that of the transient-cloud situations. More serious underestimation of the daily LE through the $\mathrm{EF}$ and $\mathrm{R}_{\mathrm{g}}$ method and stable estimation of the $\mathrm{EF}_{\mathrm{r}}$ method were intuitively found. Figure 11(d) indicates that simulated daily LE reduced by $6 \mathrm{~W} / \mathrm{m}^{2}, 12 \mathrm{~W} / \mathrm{m}^{2}$ and $18 \mathrm{~W} / \mathrm{m}^{2}$ when the amounts of the persistent cloud were $-100 \mathrm{~W} / \mathrm{m}^{2},-200 \mathrm{~W} / \mathrm{m}^{2}$ and $-300 \mathrm{~W} / \mathrm{m}^{2}$, respectively, and the reductions were much greater than those under the transient-cloud conditions.

The persistent-cloud effect on the daily LE calculation was also revealed from statistical measures at the specific upscaling time (Figure 12). In Figure 12(a), the upscaling 
results from the three methods exhibited apparently diverse upscaling biases. The overestimation through the $\mathrm{EF}_{\mathrm{r}}$ method changed slightly and the bias was still less than 4.7 $\mathrm{W} / \mathrm{m}^{2}(5.5 \%)$, demonstrating the highest accuracy. As for the other two methods, sharply increased absolute biases showed worse underestimations. The bias of the EF method was approximately $6.2-12.4 \mathrm{~W} / \mathrm{m}^{2}(7.3-14.6 \%)$ when the cloud cover was $100 \mathrm{~W} / \mathrm{m}^{2}$. It increased to more than $15 \mathrm{~W} / \mathrm{m}^{2}(17.6 \%)$ and was up to $24.1 \mathrm{~W} / \mathrm{m}^{2}(28.3 \%)$ when the cloud cover increased to $200 \mathrm{~W} / \mathrm{m}^{2}$ and $300 \mathrm{~W} / \mathrm{m}^{2}$, respectively. For the $\mathrm{R}_{\mathrm{g}}$ method, the upscaling bias was less than $9.8 \mathrm{~W} / \mathrm{m}^{2}(11.5 \%), 15.1 \mathrm{~W} / \mathrm{m}^{2}(17.7 \%)$ and $20.9 \mathrm{~W} / \mathrm{m}^{2}(24.6 \%)$ when the cloud amounts varied. The bias related to the $\mathrm{R}_{\mathrm{g}}$ method was close to that of the EF method in the low cloud cover and was smaller when the cloud amount was large; meaning that the $\mathrm{R}_{\mathrm{g}}$ method was less sensitive to the larger amount cloud than the EF method. The relative robustness of the $\mathrm{R}_{\mathrm{g}}$ method was also demonstrated in other studies (Brutsaert and Sugita, 1992).

The RMSE referred to the $\mathrm{EF}_{\mathrm{r}}$ method, varied from $5.3 \mathrm{~W} / \mathrm{m}^{2}(12.3 \%)$ to $8.9 \mathrm{~W} / \mathrm{m}^{2}$ $(20.6 \%)$ and further verified the outstanding performance of the method. The RMSE of the EF method was the largest, reaching up to $24.9 \mathrm{~W} / \mathrm{m}^{2}(57.7 \%)$, showing its largest error and unsteadiness in the daily extrapolation under severely cloudy conditions. The RMSE of the $\mathrm{R}_{\mathrm{g}}$ method was less than that of the EF method and it ranged from $9.9 \mathrm{~W} / \mathrm{m}^{2}(23.0 \%)$ to 20.3 $\mathrm{W} / \mathrm{m}^{2}(47.1 \%)$. Moreover, the $\mathrm{R}^{2}$ related to the $\mathrm{EF}_{\mathrm{r}}$ method was more than 0.97 , even with high cloud cover. The $\mathrm{R}^{2}$ related to the EF method was like that of the $\mathrm{R}_{\mathrm{g}}$ method, but the variation with the cloud was fiercer. When the persistent cloud lasted, the upscaling error was the largest near noon as well.

Similar to the reason stated in the transient-cloud situations, an expanded underestimation of the EF primarily resulted from a vast reduction of daily net radiation, caused by long-time cloud cover. In addition, accumulated discrepancies in the simulated 
fluxes related to EF calculation, as mentioned above, may also generate upscaling deviations. The reason for the invariable overestimation of the $\mathrm{EF}_{\mathrm{r}}$ method still accounted for less variation of the daily $\mathrm{ET}_{\mathrm{r}}$ which largely depended on meteorological characteristics. For the $R_{g}$ method, both greater variation of the $R_{g}$ factor and multiple reductions of the daily $R_{s}$ led to more severe undervaluation of the daily LE. It is the longer duration and massive amounts of cloud that enlarged the upscaling error, especially with respect to the EF and the $\mathrm{R}_{\mathrm{g}}$ methods.

Therefore, in the study area, the persistent cloud more inevitably deteriorates the overestimation and underestimation of daily LE extrapolating, and the $\mathrm{EF}_{\mathrm{r}}$ method shows potential advantage in the extrapolation of instantaneous LE for overcast days.

\subsection{Discussion}

The results related to the three upscaling methods at Yucheng station during the study period showed that transient cloud and persistent cloud will deteriorate the overestimation and underestimation of the daily LE extrapolation occurred in clear days. The $\mathrm{EF}_{\mathrm{r}}$ method slightly overestimated daily LE, while the other two methods both undervalued the daily LE. From the formulas for daily LE calculations in the three upscaling models, the daily LEs are determined both by upscaling factors and corresponding daily parameters. Therefore, for the estimation deviation in clear days, the overestimation regarding the $\mathrm{EF}_{\mathrm{r}}$ method was very slight, which resulted from small over calculation of the daily $\mathrm{ET}_{\mathrm{r}}$ and the constancy of $\mathrm{EF}_{\mathrm{r}}$ factor. The underestimation related to the EF method was because the instantaneous $\mathrm{EF}$ is usually lower than the daily averaged value (Lhomme \& Elguero, 1999; Hoedjes et al., 2008). Tang et al (2017b) comprehensively discussed the mechanization for the underestimation of the EF method. The underestimation from the $\mathrm{R}_{\mathrm{g}}$ method was partly stemmed from the lower value of the $\mathrm{R}_{\mathrm{g}}$ factor, which was also found in another study (Brutsaert and Sugita, 1992). 
When the transient cloud appeared before the upscaling moments or persistent cloud

559

560

561

562

563

564

565

566

567

568

569

570

571

572

573

574

575

576

577

occurred, cloud covers usually caused reductions of solar radiance and available energy, thus affecting instantaneous $\mathrm{LE}$, the upscaling factors and the upscaling results. In the $\mathrm{EF}_{\mathrm{r}}$ method, the $\mathrm{EF}_{\mathrm{r}}$ factor decreased due to the reduction of instantaneous $\mathrm{LE}$ and the unchanged instantaneous $\mathrm{ET}_{\mathrm{r}}$. The combination of a slightly varied $\mathrm{EF}_{\mathrm{r}}$ factor and an over calculated daily $\mathrm{ET}_{\mathrm{r}}$ led to relatively less change of the overvaluation of the method. For the EF method, cloudiness resulted in a decrease in $\mathrm{R}_{\mathrm{n}}$, which caused a reduction of the surface heating and tended to cause a magnification of the fraction of LE. A large reduction of the daily $R_{n}$ resulted in a more significant underestimation of the daily $L E$, compared to that of clear days. Meanwhile, for the $\mathrm{R}_{\mathrm{g}}$ method, the reduction of instantaneous LE caused a decrease in the $R_{g}$ factor, and the reduction of the daily $R_{s}$ and the $R_{g}$ factor made the underestimation more obvious. When the transient cloud appeared after the upscaling method, all upscaling factors were unchanged, and the deteriorations were totally from the estimations of daily $\mathrm{R}_{\mathrm{n}}, \mathrm{ET}_{\mathrm{r}}$ and $\mathrm{R}_{\mathrm{s}}$, respectively. Therefore, it can be found that three upscaling methods had larger estimation errors when the cloud appeared, and the quantification of the cloud effect will be helpful for improving the upscaling methods by bias correction in further study.

For the three upscaling methods themselves, the main merit of the $\mathrm{EF}_{\mathrm{r}}$ method lies in its ability to capture the effects of horizontal advection and atmospheric environmental factors (e.g., wind speed, vapor pressure deficit) on the variations of the diurnal flux. The weakness of this approach is that it requires detailed input data for atmospheric variables, e.g., the air temperature, relative humidity, global solar radiation and wind speed. In the context of remote sensing applications, requirements regarding auxiliary information may further limit the operational utility of the upscaling method. Unlike the $\mathrm{EF}_{\mathrm{r}}$ method, the EF method and the $\mathrm{R}_{\mathrm{g}}$ method need less meteorological data as input, as only instantaneous LE, daily $\mathrm{R}_{\mathrm{n}}$ and 
$\mathrm{R}_{\mathrm{g}}$ are required. The comparison of the EF method and the $\mathrm{R}_{\mathrm{g}}$ method showed that the $\mathrm{R}_{\mathrm{g}}$ method was less sensitive to the large amount of cloud cover than the EF method.

In addition, some variability in the flux data in the study is caused by outright errors attributable to the problems of the ALEX input and related factors. Additionally, there is no consideration of regional discrepancies and seasonal differences, which may also influence the applications of these upscaling methods. And the definition of the persistent cloud should be explored to be more close to the reality.

For the validations of the performances of the three upscaling methods, it is necessary and urgent to compare the daily LE extrapolation to the measured data. Because it is difficult to find enough days that coincide with the cloudy situation settings in the study, only validations of the daily LE on completely clear days were provided. After acquiring more elaborate and longer periods of in situ measurements in the future, the results on cloudy days will be validated.

All of these constraints should be taken into consideration, and subsequent work is required to enable further analysis to collect long time data measurements and select an optimal upscaling procedure for different regions and terrestrial climates.

\section{Conclusion}

Studying the cloud effect on temporal upscaling of instantaneous ET is significant and meaningful for developing a more accurate upscaling method to obtain accurate daily or longer time scale ET. This study attempted to evaluate the cloud effect with different amounts and durations on three representative temporal upscaling schemes at Yucheng station during the period from late April 2009 to late October 2010.

Overall, it was found that cloud would deteriorate the undervaluation or overvaluation of daily LE through the three upscaling methods. Persistent cloud had a more serious effect than the transient cloud. And for transient cloud, upscaling results had more discrepancies 
when the cloud appeared before the upscaling moment than after. When cloud cover increased, the effects on the upscaling factors and upscaling results both increased proportionally. Both transient cloud and persistent cloud had more serious effects at noontime.

As for the three upscaling schemes, the $\mathrm{EF}_{\mathrm{r}}$ method performed best in both the transient-cloud and persistent-cloud situations, with the least biases, of less than $4.7 \mathrm{~W} / \mathrm{m}^{2}$ $(5.5 \%)$ and RMSEs less than $8.9(20.6 \%) \mathrm{W} / \mathrm{m}^{2}$. The EF method had a similar performance to the $\mathrm{R}_{\mathrm{g}}$ method when transient cloud occurred, but it performed worst under the persistent-cloud condition. The upscaling bias and RMSE related to the EF method were as high as $24.1 \mathrm{~W} / \mathrm{m}^{2}(28.3 \%)$ and $24.9 \mathrm{~W} / \mathrm{m}^{2}(57.7 \%)$, respectively. The $\mathrm{R}_{\mathrm{g}}$ method had an intermediate accuracy, with biases of less than $20.9 \mathrm{~W} / \mathrm{m}^{2}$ and RMSEs less than $20.3 \mathrm{~W} / \mathrm{m}^{2}$ $(47.1 \%)$. Therefore, the $\mathrm{EF}_{\mathrm{r}}$ method was verified to have the best accuracy in capturing the variation of the diurnal LE in the cloudy situations. When intensive ground-based measurements of meteorological variables are readily available, the $\mathrm{EF}_{\mathrm{r}}$ method is recommended for the extrapolation of instantaneous LE, even for cloudy days.

This study provides scientific guidance for the development and choice of an operational and more accurate ET-upscaling method used in cloudy weather in other regions. It also provides a reference method for other studies to evaluate the cloud effects with different settings, according to different durations and amounts of cloud cover.

Acknowledgments: The work was supported by the National Natural Science Foundation of China under Grant No. 41571351, 41571352 and 41231170; the International Science and Technology Cooperation Program of China under Grant No. 2014DFE10220 and the National Basic Research Program of China (973 Program) under Grant No. 2013CB733402. 
631

632

633

634

635

636

637

638

639

640

641

642

643

644

645

646

647

648

649

650

651

652

653

654

655

656

657

\section{Reference}

Allen, R. G., Pereira, L.S., Raes, D., \& Smith, M. (1998). “Crop evapotranspiration - Guidelines for computing crop water requirements - FAO Irrigation and drainage paper 56." FAO, 56.

Allen, R. G., Pruitt, W. O., Wright, J. L., Howell, T. A., Ventura, F., \& Snyder, R., et al. (2006). “A recommendation on standardized surface resistance for hourly calculation of reference ET o, by the FAO 56 Penman-Monteith method.” Agr. Water Manage, 81(1-2), 1-22.

Allen, R. G., Tasumi, M., Morse, A., Trezza, R., Wright, J. L., \& Bastiaanssen, W., et al. (2007). "Satellite-based energy balance for mapping evapotranspiration with internalized calibration (metric) - applications.” J. Irrig. Drain. E., 133(4), 395-406.

Anderson, M. C., Norman, J. M., Diak, G. R., Kustas, W. P., \& Mecikalski, J. R. (1997). “A two-source time-integrated model for estimating surface fluxes using thermal infrared remote sensing." Remote Sens. Environ., 60(2), 195-216.

Anderson, M. C., Norman, J. M., Meyers, T. P., \& Diak, G. R. (2000). “An analytical model for estimating canopy transpiration and carbon assimilation fluxes based on canopy light-use efficiency.” Agr. Forest Meteorol., 101(4), 265-289.

ASCE-EWRI. (2005). “The ASCE standardized reference evapotranspiration equation. Technical committee report to the environmental and water resources Institute of the American Society of Civil Engineers from the Task Committee on Standardization of Reference Evapotranspiration." ASCE-EWRI, 1801 Alexander Bell Drive, Reston, VA 20191-4400, 173 pp.

Bastiaanssen, W.G.M. (2000). "SEBAL-based sensible and latent heat fluxes in the irrigated Gediz basin, turkey." J. Hydrol., 229(1-2), 87-100.

Brutsaert, W., \& Sugita, M. (1992). “Application of self-preservation in the diurnal evolution of the surface energy budget to determine daily evaporation.” J. Geophys. Res.-Atmos., 97(D17), 99-104.

Bussieres, N., \& Goita, K. (1997). "Evaluation of strategies to deal with cloudy situation in satellite evapotranspiration algorithm." Proceedings of the third International Workshop NHRI symposium 17, 16-18 October 1996, NASA, Goodard Space Flight Center, Greenbelt, Maryland, USA: 33-43. 
Cammalleri, C., Anderson, M.C., \& Kustas, W.P. (2014). "Upscaling of evapotranspiration fluxes from instantaneous to daytime scales for thermal remote sensing applications." Hydrol. Earth Syst. Sc., 18, 1885-1894.

Carlson, T. N., Capehart, W. J., \& Gillies, R. R. (1995). "A new look at the simplified method for remote sensing of daily evapotranspiration.” Remote Sens. Environ., 54(2), 161-167.

Colaizzi, P. D., Evett, S. R., Howell, T. A., \& Tolk, J. A. (2006). “Comparison of five models to scale daily evapotranspiration from one-time-of-day measurements”. T. Asae., 49, 1409-1417.

Chávez, J.L, Neale, C.M.U, Prueger, J.H., \& Kustas, W.P. (2008). "Daily evapotranspiration estimates from extrapolating instantaneous airborne remote sensing ET values." Irrigation Sci., 27(1), 67-81.

Courault, D., Seguin, B., \& Olioso, A. (2005). "Review on estimation of evapotranspiration from remote sensing: from empirical to numerical modeling approaches.” Irrig. Drain. Syst., 19(3), 223-249.

Crago, R.D. (1996). “Conservation and variability of the evaporative fraction during the daytime.” J. Hydrol., 180(1-4), 173-194.

Delogu, E., Boulet, G., Olioso, A., Coudert, B., Chirouze, J., Ceschia, E., Le Dantec, V., Marloie, O., Chehbouni, G., \& Lagouarde, J.P. (2012). "Temporal variations of evapotranspiration: reconstruction using instantaneous satellite measurements in the thermal infrared domain.” Hydrol. Earth Syst. Sci., 9(2), 1699-17.

Galleguillos, M., Jacob, F., Prévot, L., Lagacherie, P., \& Liang, S. (2011). “Mapping daily evapotranspiration over a mediterranean vineyard watershed.” IEEE Geosci. Remote Sens. Lett., $8(8), 168-172$.

Gentine, P., Entekhabi, D., Chehbouni, A., Boulet, G., \& Duchemin, B. (2007). "Analysis of evaporative fraction diurnal behaviour.” Agr. Forest Meteorol., 143(1-2), 13-29.

Gómez, M., Olioso, A., Sobrino, J.A, \& Jacob F. (2005). "Retrieval of evapotranspiration over the alpilles/reseda experimental site using airborne polder sensor and a thermal camera." Remote Sens. Environ., 96(3-4), 399-408. 
Hoedjes, J. C. B., Chehbouni, A., Jacob, F., Ezzahar, J., \& Boulet, G. (2008). "Deriving daily evapotranspiration from remotely sensed instantaneous evaporative fraction over olive orchard in semi-arid Morocco”. J. Hydrol, 354, 53-64.

Houborg, R., Anderson, M. C., Norman, J. M., Wilson, T., \& Meyers, T. (2009). “Intercomparison of a 'bottom-up' and 'top-down' modeling paradigm for estimating carbon and energy fluxes over a variety of vegetative regimes across the U.S.” Agr. Forest Meteorol.,149(11), 1875-1895.

Jackson, R. D., Hatfield, J. L., Reginato, R. J., Idso, S. B., \& Pinter, P. J. (1983). “Estimation of daily evapotranspiration from one time-of-day measurements.” Agr. Water Manage, 7(1-3), 351-362.

Lhomme, J. P., \& Elguero, E. (1999). "Examination of evaporative fraction diurnal behavior using a soil-vegetation model coupled with a mixed-layer model.” Hydrol. Earth Syst. Sc., 3(2), 259-270.

Li, Z-L., Tang, R., Wan, Z., Bi, Y., Zhou, C., Tang, B-H., Yan, G., \& Zhang, X. (2009). “A review of current methodologies for regional evapotranspiration estimation from remotely sensed data." Sensors, 9, 3801-3853.

Long, C. N., \& Ackerman, T. P. (2000). "Identification of clear skies from broadband pyranometer measurements and calculation of downwelling shortwave cloud effects.” J. Geophys. Res. Atmos., 105(D12), 15609-15626.

Long, C. N., Ackerman, T. P., Gaustad, K. L., \& Cole, J. N. S. (2006). "Estimation of fractional sky cover from broadband shortwave radiometer measurements." J. Geophys. Res. D11204 Doi/jd, 111(D11), 1937-1952.

Lu, J., Tang, R., Tang, H., \& Li, Z. L. (2013). "Derivation of daily evaporative fraction based on temporal variations in surface temperature, air temperature, and net radiation." Remote Sens., 5(10), 5369-5396.

Lu, J., Tang, R., Tang, H., Li, Z. L., Zhou, G., \& Shao, K., et al. (2014). “Daily evaporative fraction parameterization scheme driven by day-night differences in surface parameters: improvement and validation”. Remote Sens., 6(5), 4369-4390.

Nichols, W. E., \& Cuenca, R. H. (1993). "Evaluation of the evaporative fraction for parameterization of the surface energy balance.” Water Resour. Res., 29(11), 3681-3690. 
Niel, T. G. V., Mcvicar, T. R., Roderick, M. L., Dijk, A. I. J. M. V., Renzullo, L. J., \& Gorsel, E. V. (2011). "Correcting for systematic error in satellite-derived latent heat flux due to assumptions in temporal scaling: assessment from flux tower observations.” J. Hydrol, 409(1-2), 140-148.

Niel, T. V., \& Mcvicar, T. R. (2012). "Upscaling latent heat flux for thermal remote sensing studies: comparison of alternative approaches and correction of bias.” J. Hydrol, 468(4), 35-46.

Rasmus, H., Marthac, A., Johnm, N., Tim, W., \& Tilden, M. (2009). "Intercomparison of a 'bottom-up' and 'top-down' modeling paradigm for estimating carbon and energy fluxes over a variety of vegetative regimes across the u.s.” Agr. Forest Meteorol., 149(11), 1875-1895.

Rowntree, P.R. (1991). “Atmospheric parameterization schemes for evaporation over land: basic concepts and climate modeling aspects.” In: T.J. Sehmuggeand J.C. Andr6 (Editors), Land Surface Evaporation. Springer, New York, 5-29.

Ryu, Y., Baldocchi, D. D., Black, T. A., Detto, M., Law, B. E., \& Leuning, R., et al. (2012). "On the temporal upscaling of evapotranspiration from instantaneous remote sensing measurements to 8-day mean daily-sums.” Agr. Forest Meteorol.,152(1), 212-222.

Shuttleworth, W. J. (1989). "FIFE: The variation in energy partition at surface flux sites." Iahs Publication.

Sugita, M., \& Brutsaert, W. (1991). "Daily evaporation over a region from lower boundary layer profiles.” Water Resour. Res., 27:747-752.

Tang, R, Li, Z-L, Jia, Y, Li, C, Sun, X, Kustas, W.P., Anderson, M.C. (2011). “An intercomparison of three remote sensing-based energy balance models using large aperture scintillometer measurements over a wheat-corn production region.” Remote Sens. Environ., 115, 3187-3202.

Tang, R., Li, Z. L., \& Sun, X. (2013). “Temporal upscaling of instantaneous evapotranspiration: an intercomparison of four methods using eddy covariance measurements and MODIS data." Remote Sens. Environ., 138(6), 102-118.

Tang, R., Li, Z., Sun, X., \& Bi, Y. (2017a). “Temporal upscaling of instantaneous evapotranspiration on clear-sky days using the constant reference evaporative fraction method with fixed or variable surface resistances at two cropland sites.” J. Geophys. Res-Atmos., 122. 784-801. 
739 Tang, R., \& Li, Z. (2017b). “An improved constant evaporative fraction method for estimating daily 740 evapotranspiration from remotely sensed instantaneous observations." Geophys. Res. Lett. 44, $741 \quad 2319-2326$

742 Teixeira, A., Bastiaanssen, W.G.M., Ahmad, M.D., \& Bos, M.G. (2009). "Reviewing SEBAL input 743 parameters for assessing evapotranspiration and water productivity for the low-middle São 744 Francisco River basin, Brazil. Part A: calibration and validation.” Agr. Forest Meteorol.. 149, $745 \quad 462-476$.

746 Trezza R. (2002). "Evapotranspiration using a satellite-based surface energy balance with 747 standardized ground control.” Ph.D. dissertation, USU, Logan, UT, 339 pp.

748 Xu, T., Liu, S., Xu, L., Chen, Y., Jia, Z., \& Xu, Z., et al. (2015). "Temporal upscaling and 749 reconstruction of thermal remotely sensed instantaneous evapotranspiration." Remote Sens., 7(3), $750 \quad 3400-3425$.

751 Zhang, L., \& Lemeur, R. (1995). "Evaluation of daily evapotranspiration estimates from 752 instantaneous measurements.” Agr. Forest Meteorol., 74(1-2), 139-154. 
Table 1. The input parameters about soil and vegetation characteristic in ALEX model

$$
\text { at Yucheng station }
$$

\begin{tabular}{ccc}
\hline Quantities & Units & Values \\
\hline Measure height & $\mathrm{m}$ & $2.93 ; 4.2$ \\
Vegetation type & $/$ & Wheat; corn \\
Vegetation height & $\mathrm{m}$ & $0-0.6 ; 0-2.4$ \\
Leaf area index & $\mathrm{m}^{2} / \mathrm{m}^{2}$ & $0-10$ \\
Rooting depth & $\mathrm{m}$ & 0.5 \\
Soil texture & $/$ & loam \\
sand & $/$ & 0.42 \\
silt & $/$ & 0.4 \\
clay & $/$ & 0.18 \\
Bulk density & $\mathrm{g} / \mathrm{cm}^{3}$ & 1.5 \\
Moisture release parameter & $/$ & 4.5 \\
Air entry potential & $\mathrm{J} / \mathrm{kg}^{2}$ & -1.1 \\
Saturated hydraulic conductivity & $\mathrm{K} \cdot \mathrm{g} \cdot \mathrm{s} / \mathrm{m}^{3}$ & $3.7 \times 10^{-4}$ \\
soil water content $(0-2 \mathrm{~m})$ & $\mathrm{m} / \mathrm{m}^{3}$ & $0.07-0.21,0.43($ saturated $)$ \\
\hline
\end{tabular}


Table 2. DOY (Day of year) of selected clear days from late April of 2009 to late October of 2010

\begin{tabular}{|c|c|}
\hline Year & DOY of clear days \\
\hline 2009 & $\begin{array}{llllllllllllll}123 & 124 & 126 & 145 & 152 & 161 & 171 & 173 & 174 & 175 & 176 & 278 & 279 & 297\end{array}$ \\
\hline 2010 & $\begin{array}{lllllll}085 & 087 & 113 & 118 & 119 & 121 & 277\end{array}$ \\
\hline
\end{tabular}


Table 3. The appearing time of transient cloud and persistent cloud

\begin{tabular}{|c|c|c|c|c|c|c|c|c|c|}
\hline \multirow{2}{*}{$\begin{array}{l}\text { Upscaling } \\
\text { time }\end{array}$} & \multicolumn{9}{|c|}{ Cloud appearing time } \\
\hline & $\begin{array}{c}8: 00 \sim ~ \\
9: 00\end{array}$ & $\begin{array}{l}9: 00 \sim ~ \\
10: 00\end{array}$ & $\begin{array}{c}10: 00 \sim ~ \\
11: 00\end{array}$ & $\begin{array}{c}11: 00 \sim \\
12: 00\end{array}$ & $\begin{array}{c}12: 00 \sim \\
13: 00\end{array}$ & $\begin{array}{c}13: 00 \sim ~ \\
14: 00\end{array}$ & $\begin{array}{c}14: 00 \sim \\
15: 00\end{array}$ & $\begin{array}{c}15: 00 \sim \\
16: 00\end{array}$ & $\begin{array}{r}16: 00 \sim ~ \\
17: 00\end{array}$ \\
\hline $9: 30$ & $* \#$ & & $※ \#$ & $\#$ & $\#$ & $\#$ & $\#$ & $\#$ & $\#$ \\
\hline $10: 30$ & \# & $* \#$ & & $※ \#$ & \# & \# & \# & \# & \# \\
\hline $11: 30$ & \# & \# & $* \#$ & & $※ \#$ & \# & \# & $\#$ & \# \\
\hline $12: 30$ & $\#$ & \# & $\#$ & $* \#$ & & $※ \#$ & $\#$ & $\#$ & \# \\
\hline $13: 30$ & $\#$ & \# & $\#$ & $\#$ & $* \#$ & & $※ \#$ & \# & \# \\
\hline $14: 30$ & $\#$ & \# & \# & \# & \# & $* \#$ & & ※\# & \# \\
\hline
\end{tabular}

* and $※$ represent transient cloud that appears one hour before and one hour after upscaling time, respectively ; \# represents persistent cloud lasting the whole daytime except upscaling time. 


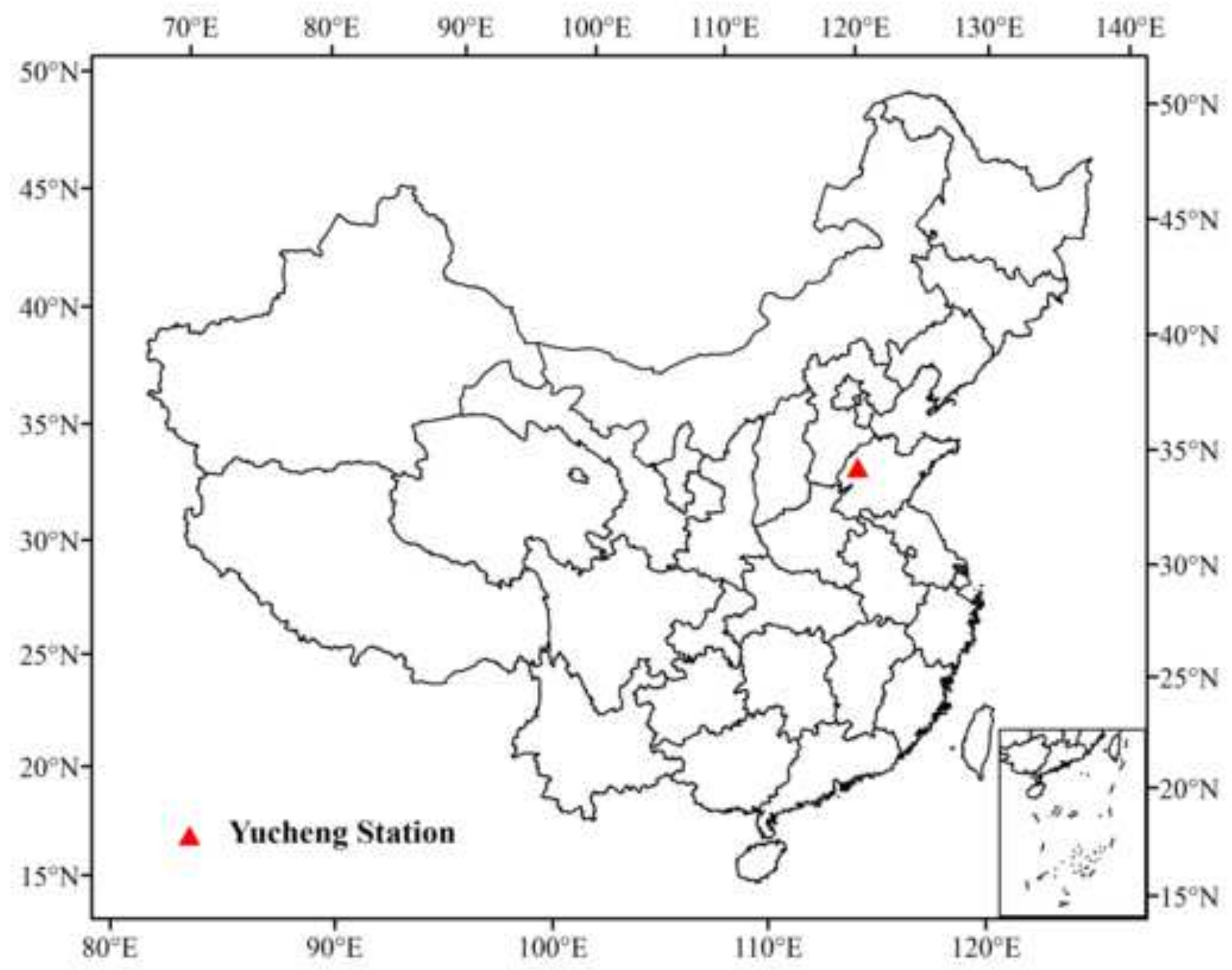




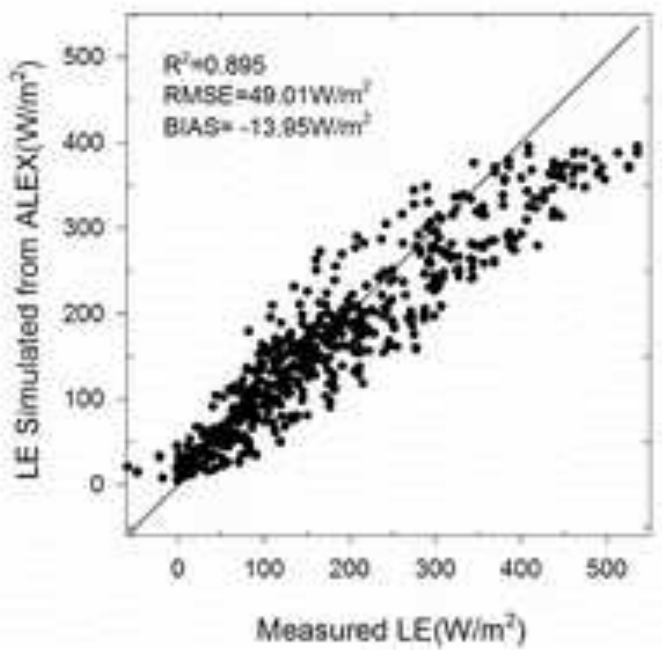

(a)

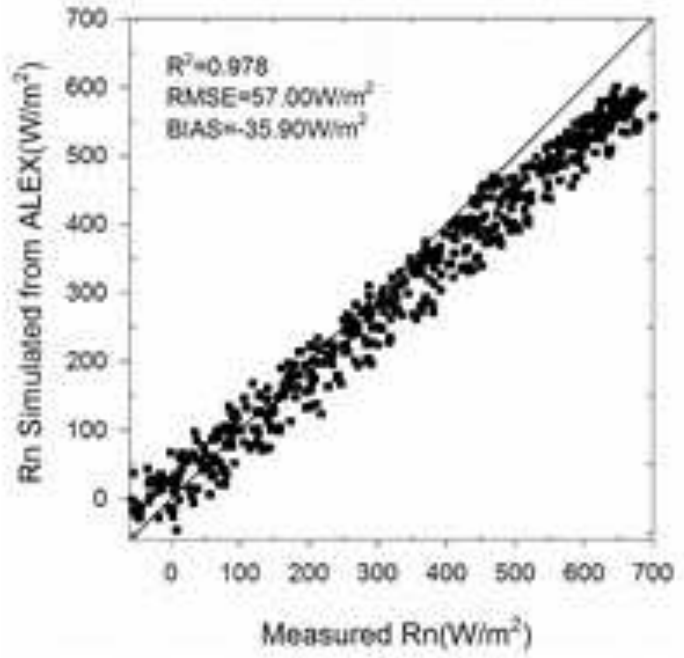

(c)

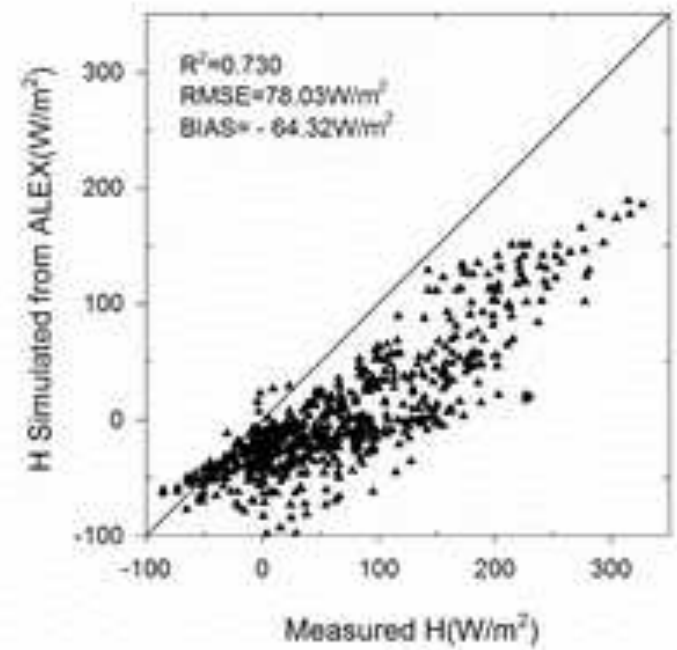

(b)

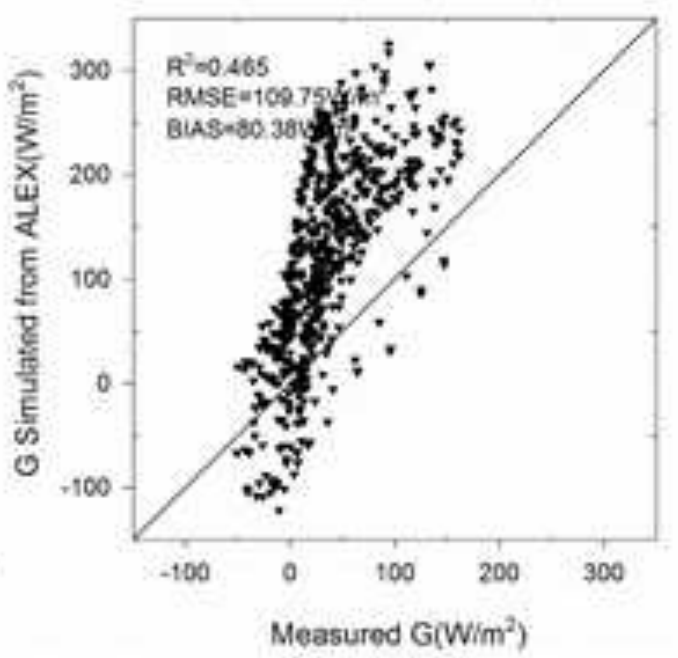

(d) 


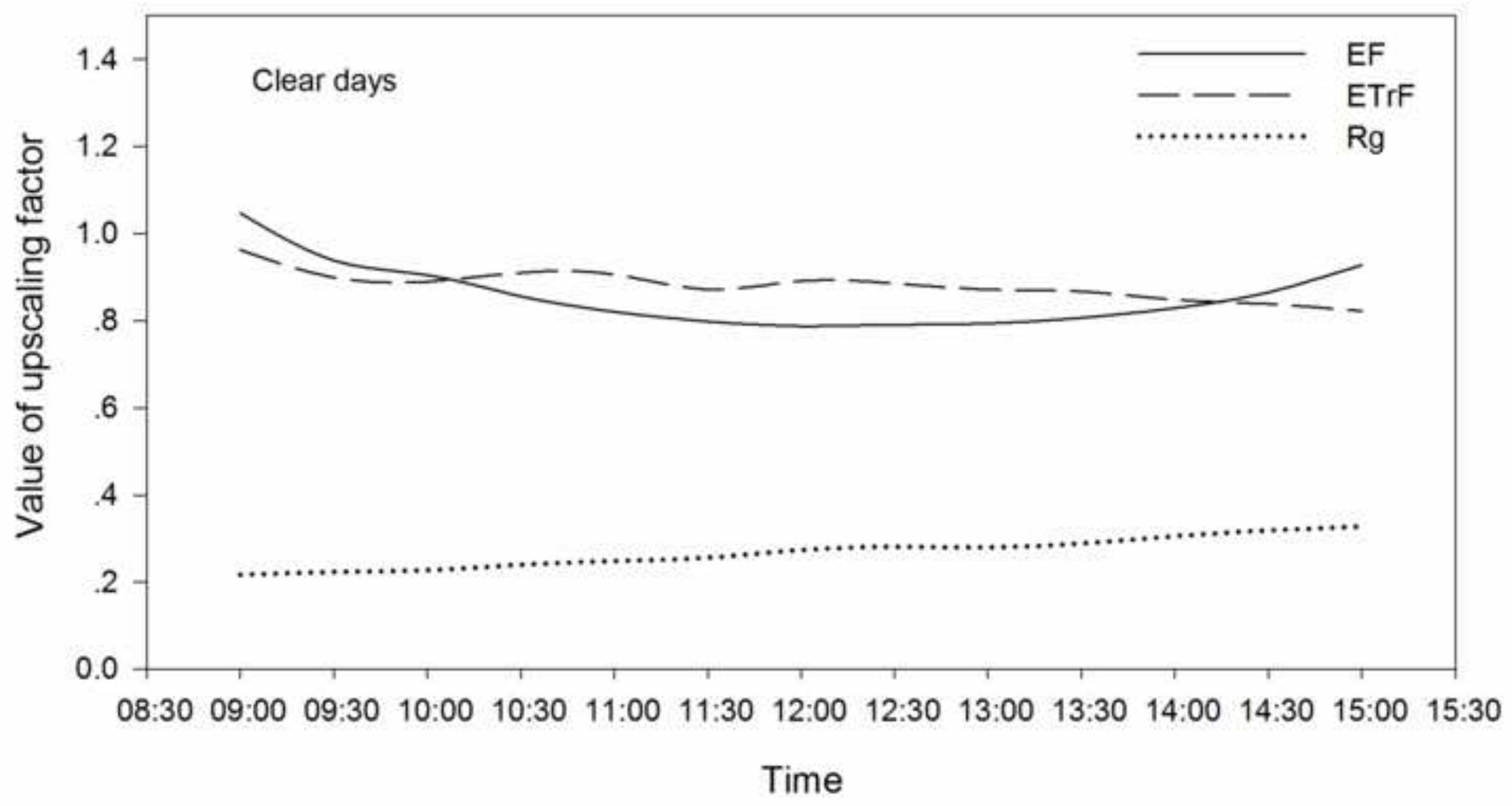




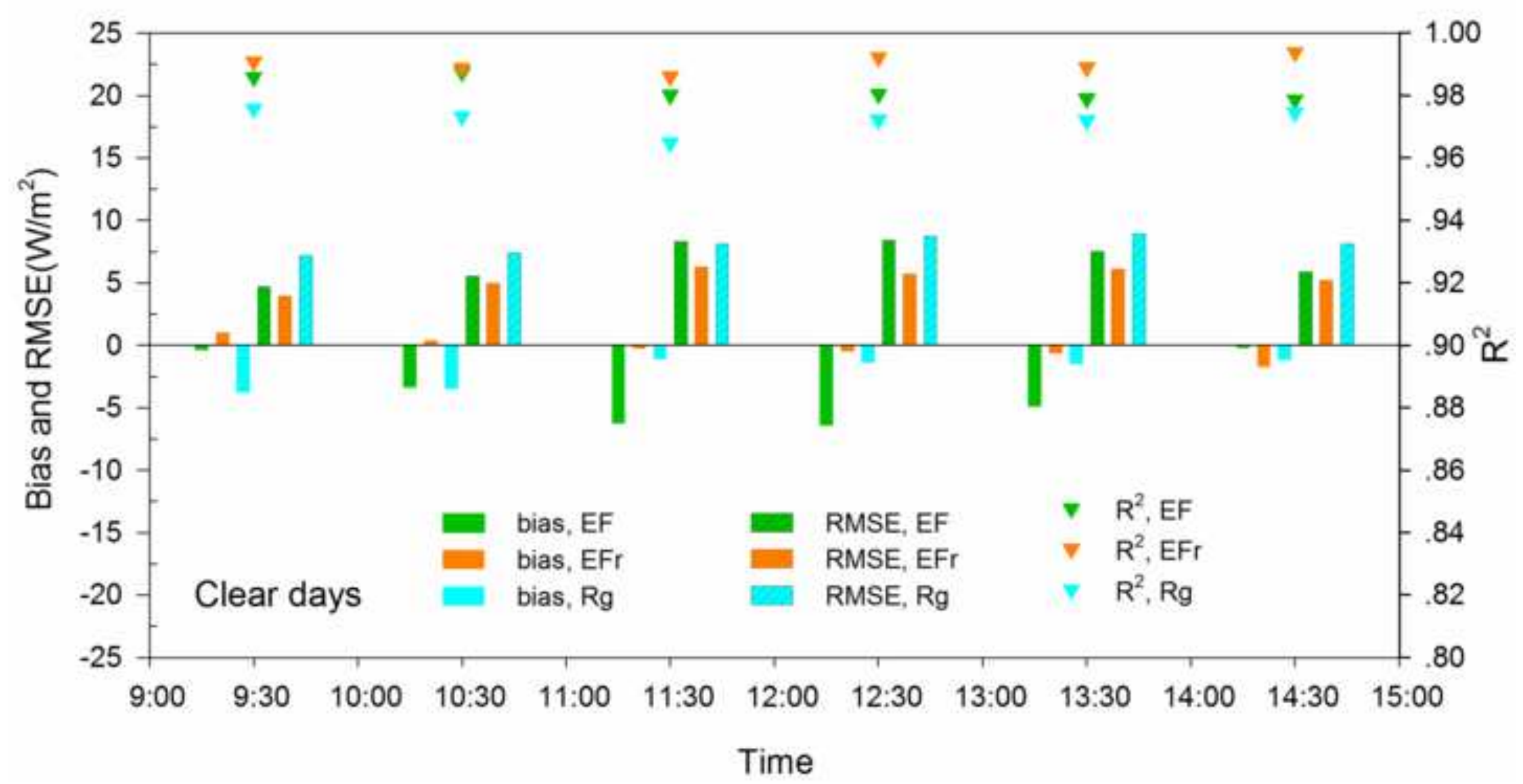




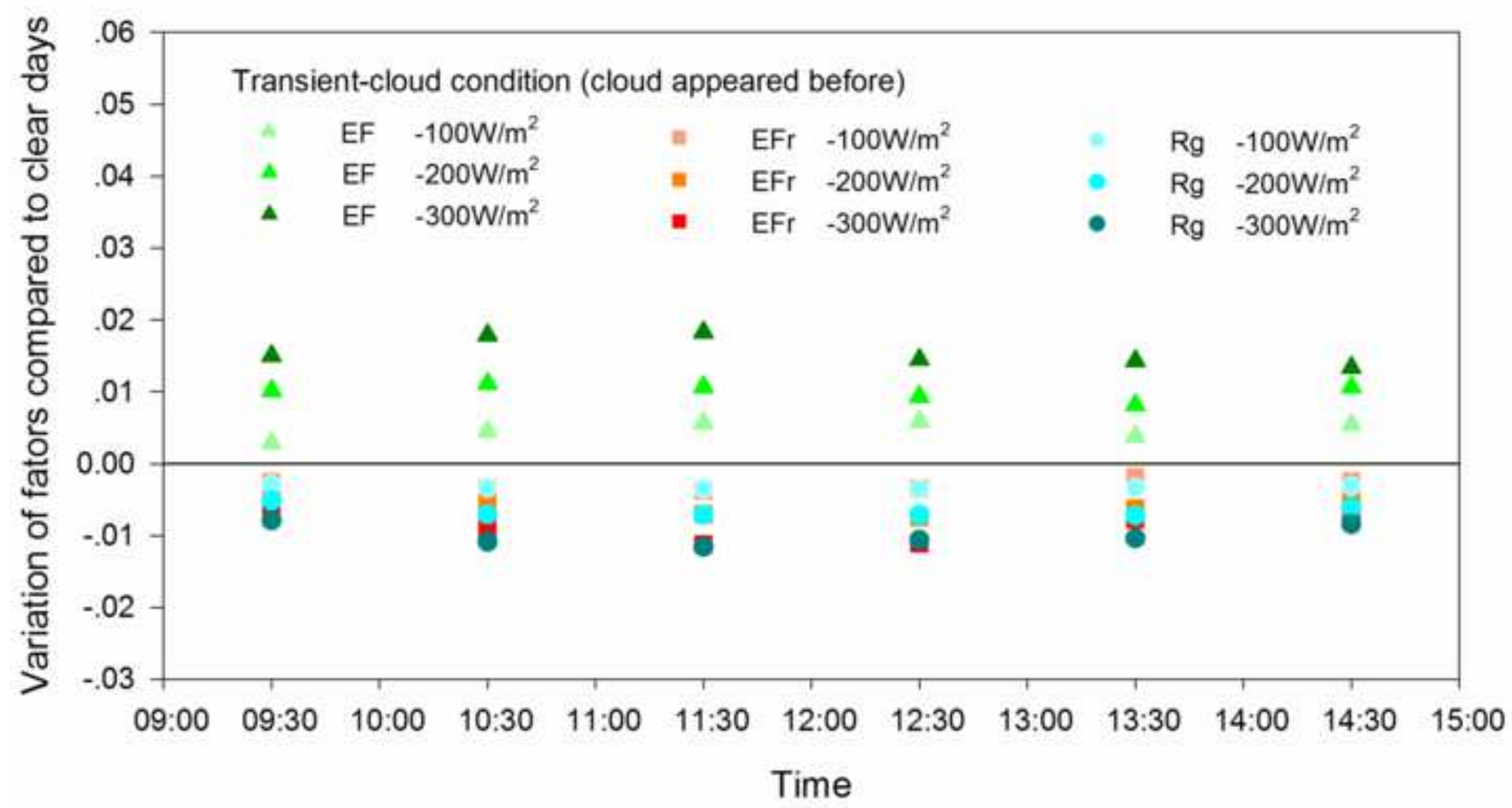



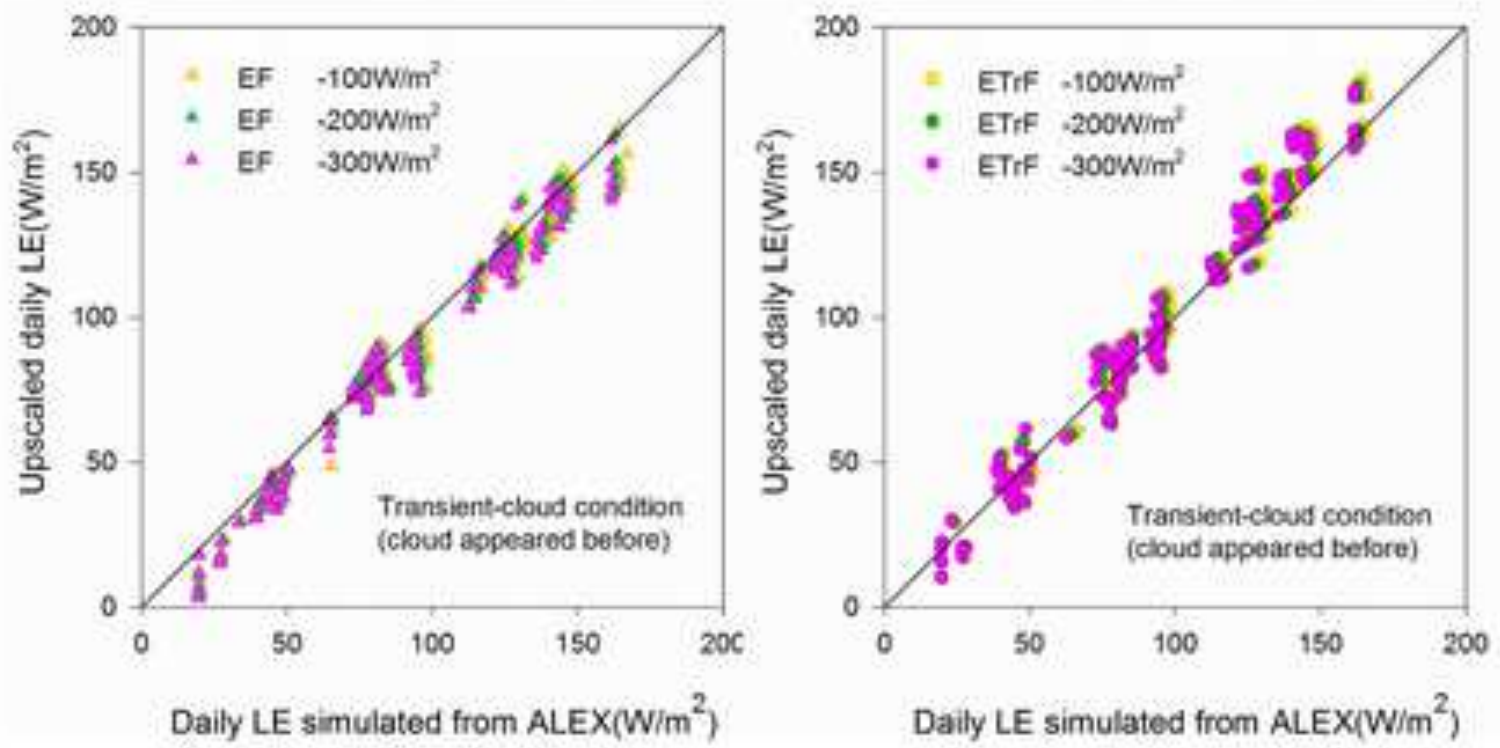

(a)
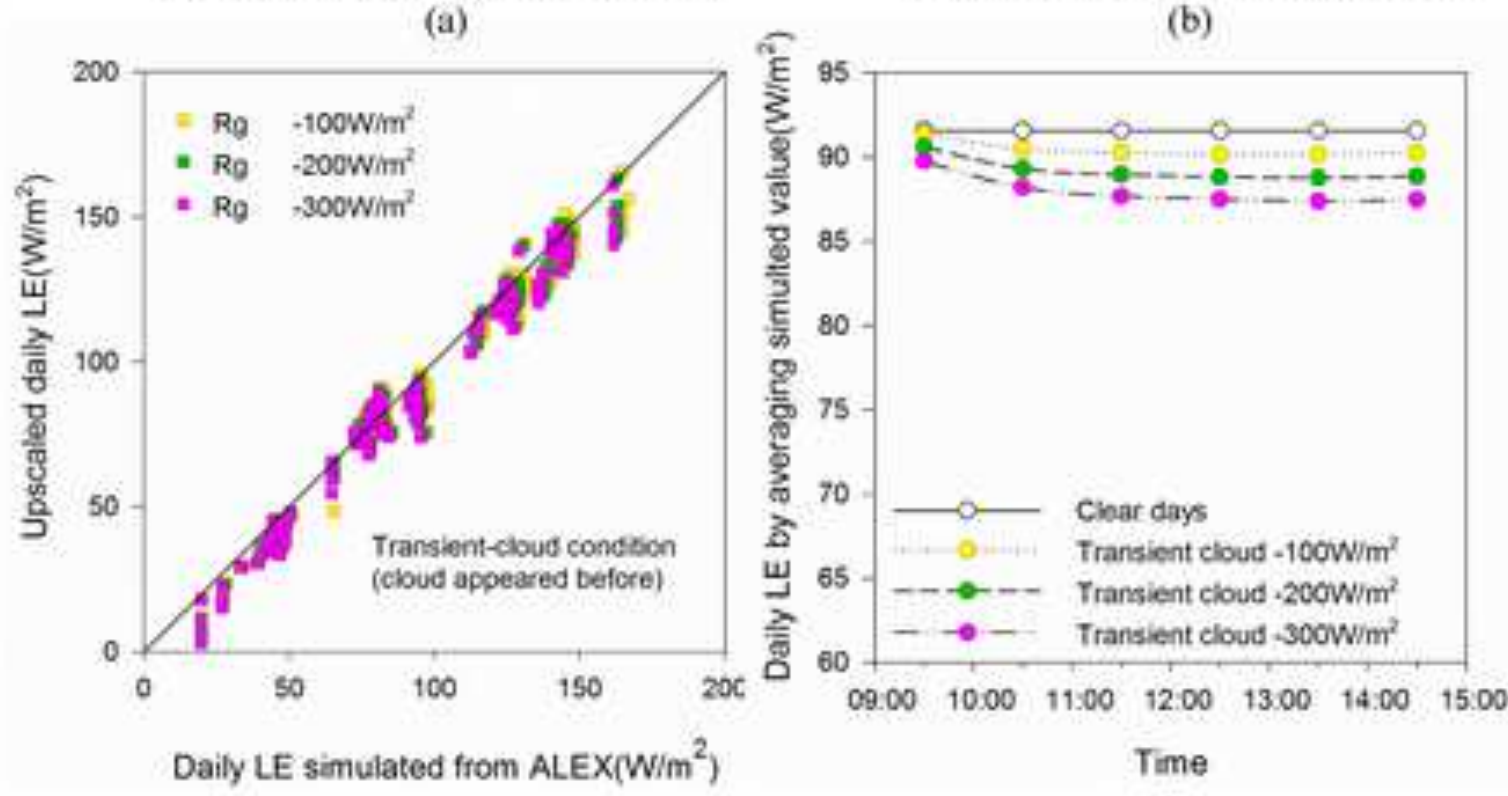

(c)

(d) 

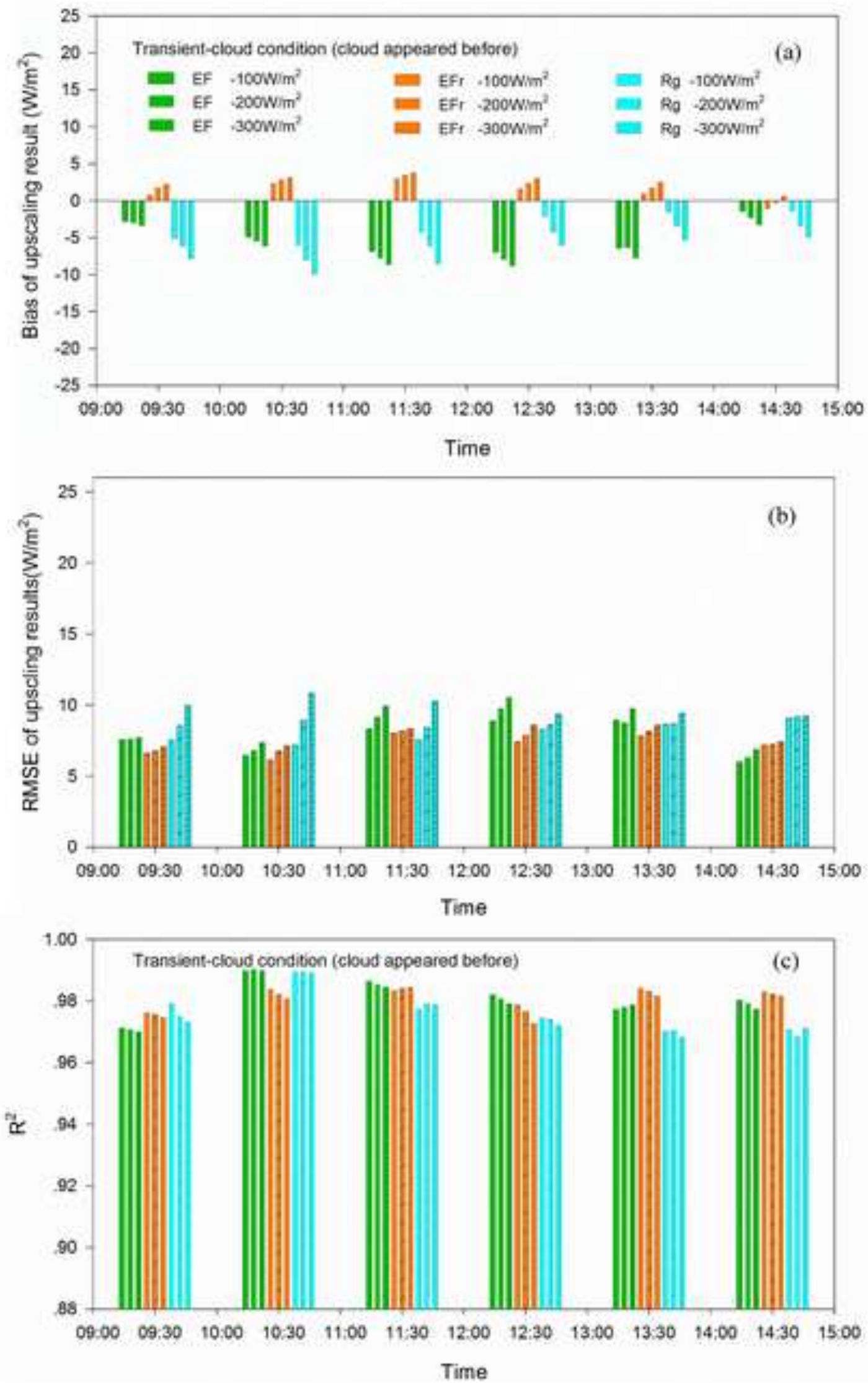


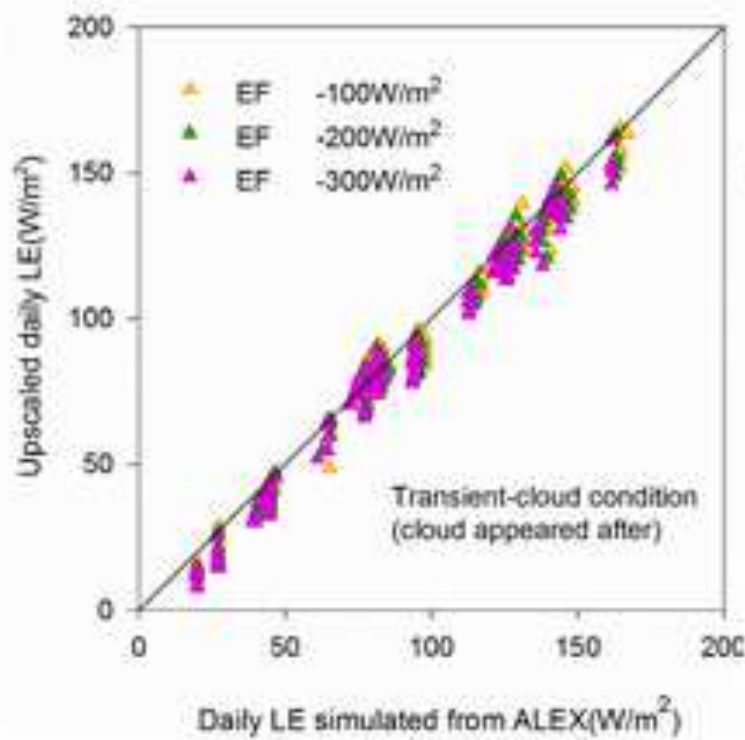

(a)

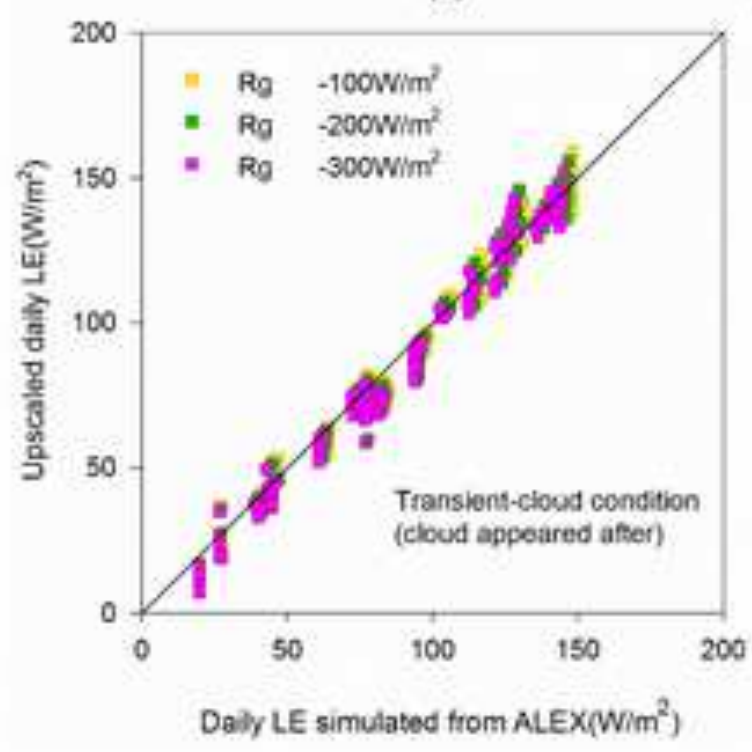

(c)

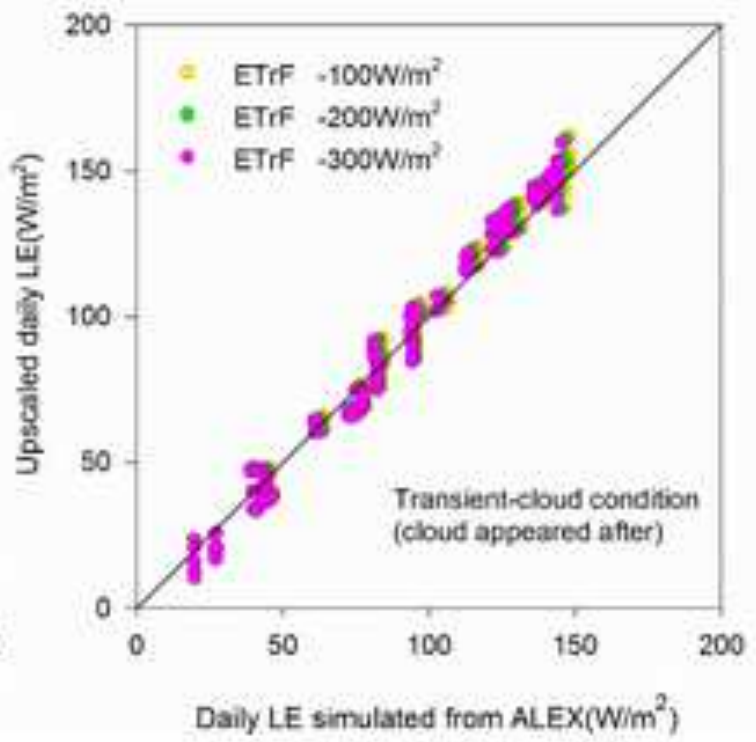

(b)

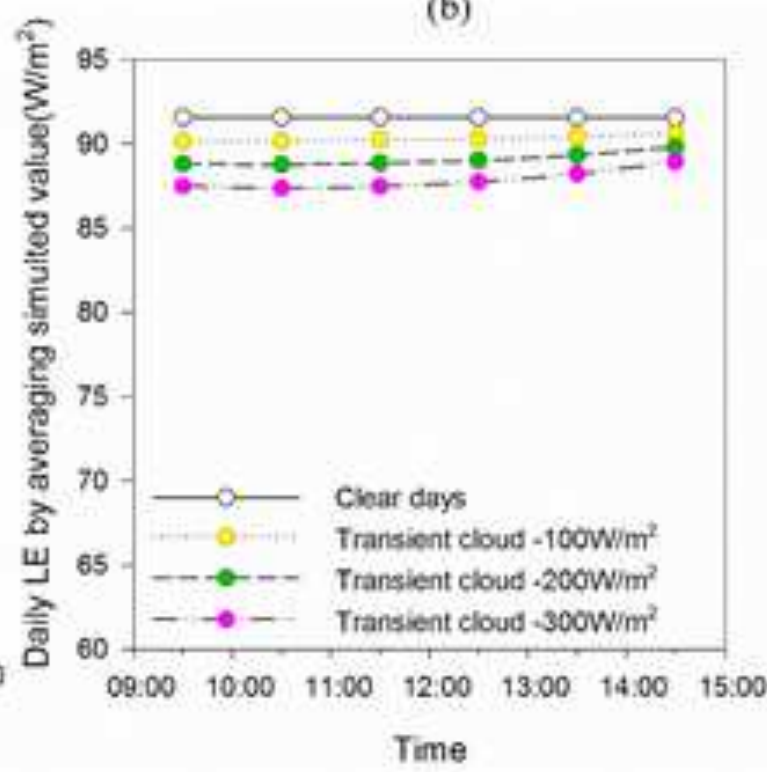

(d) 

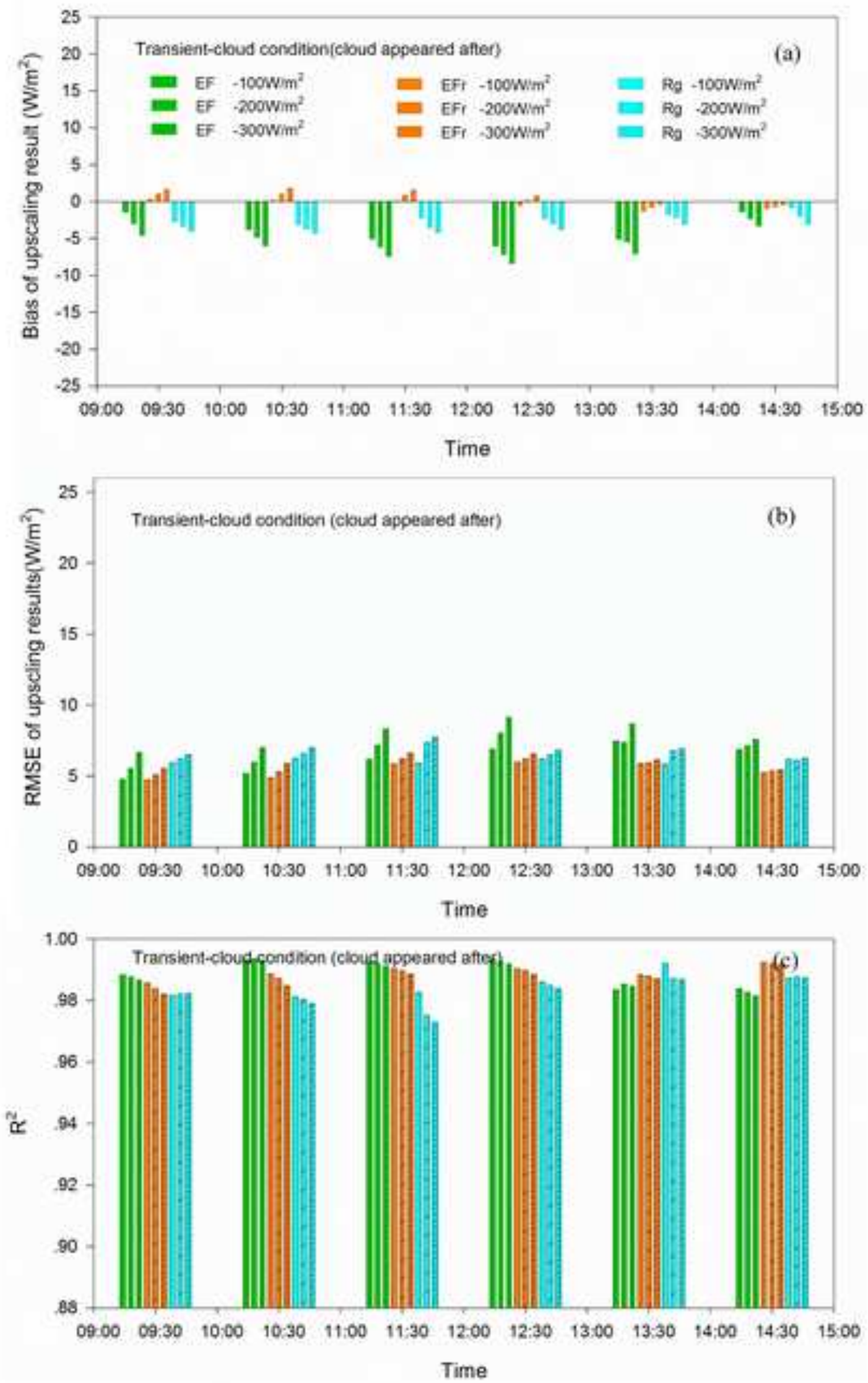


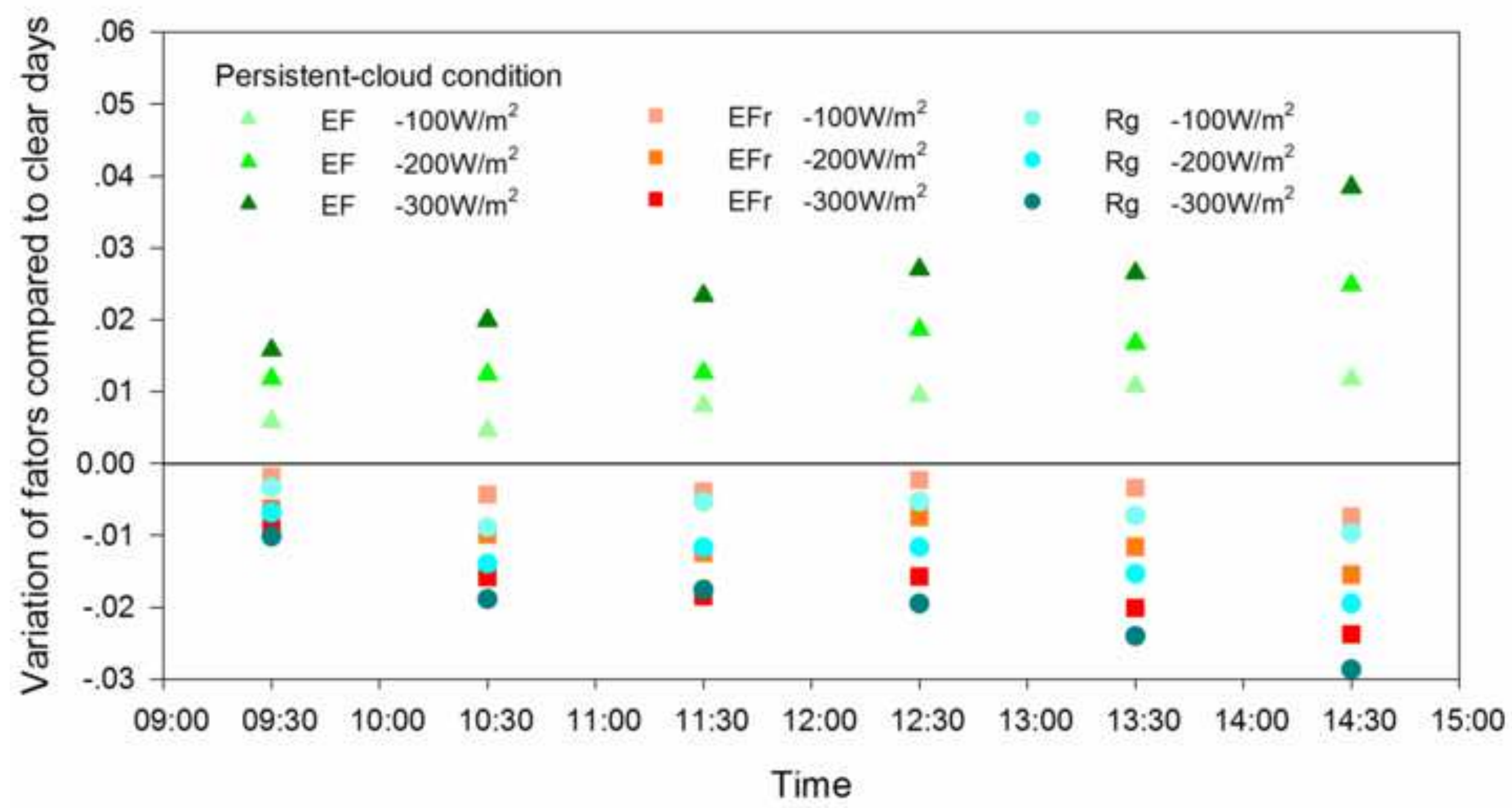




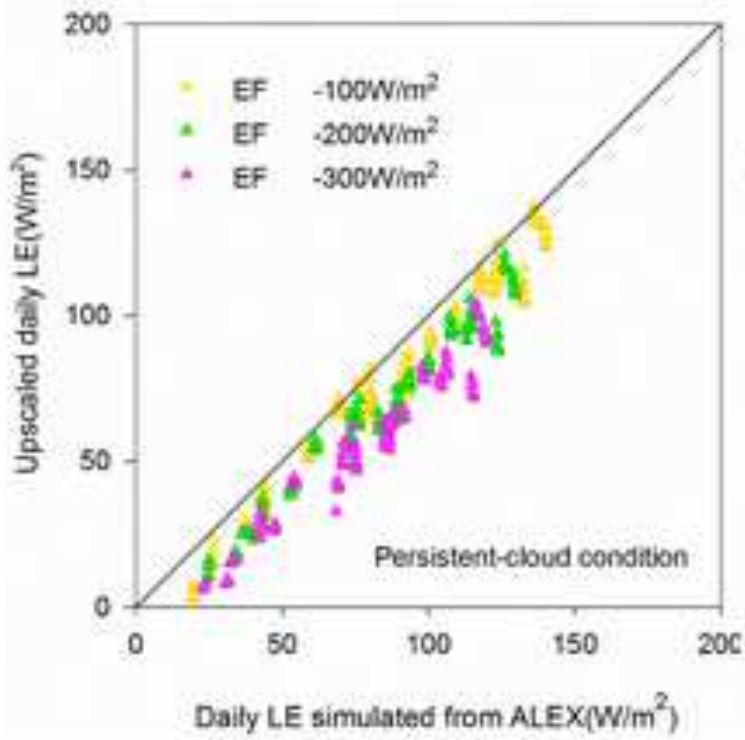

(a)

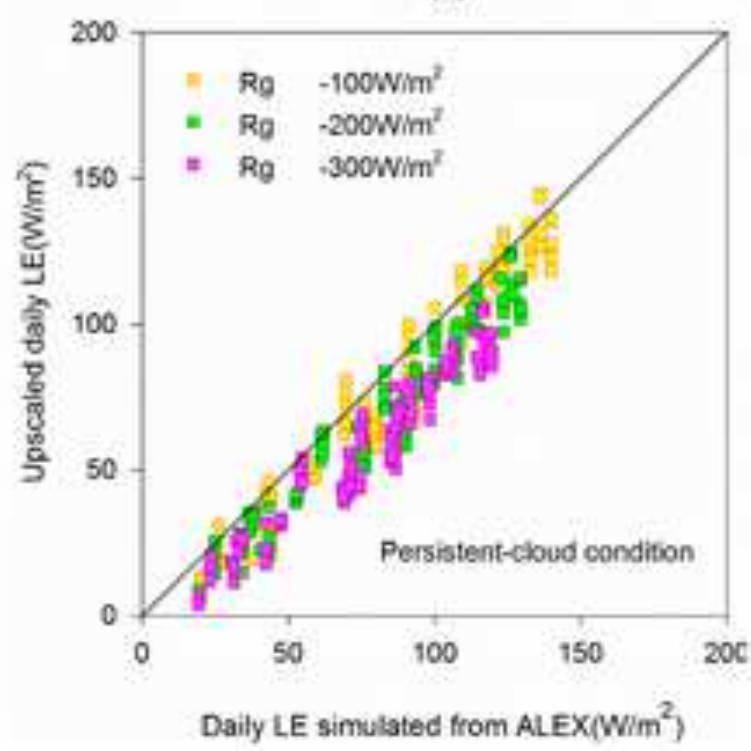

(c)

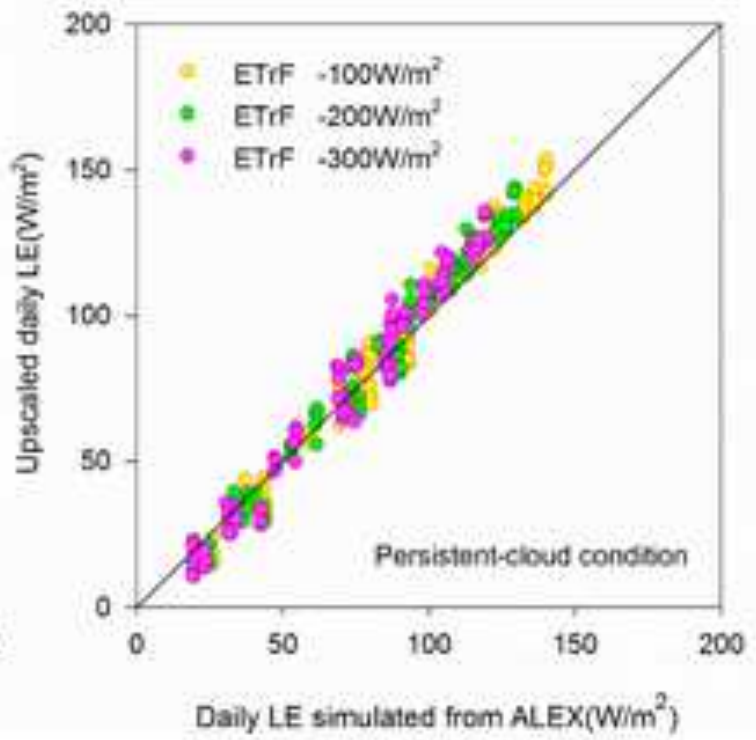

(b)

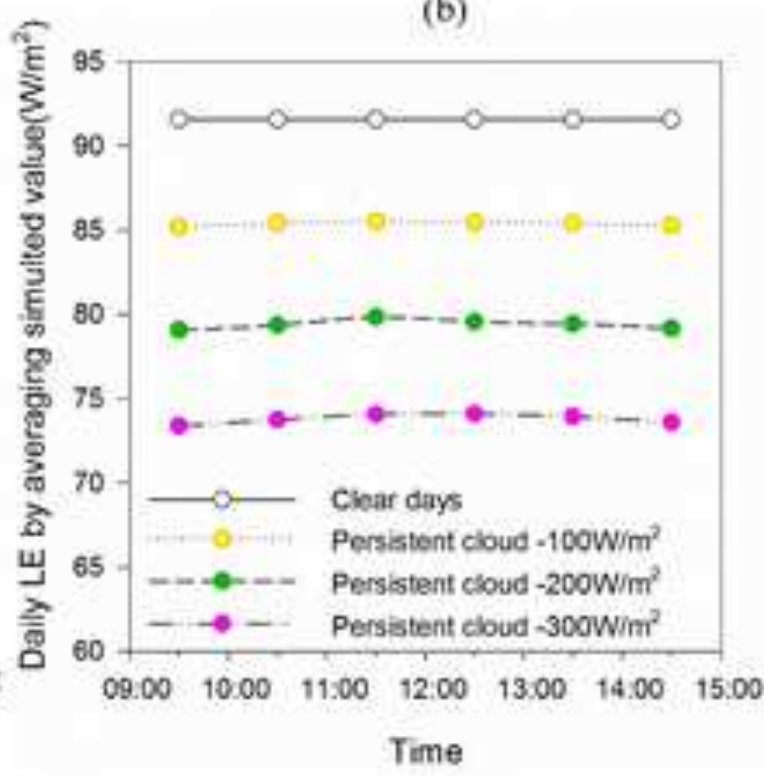

(d) 

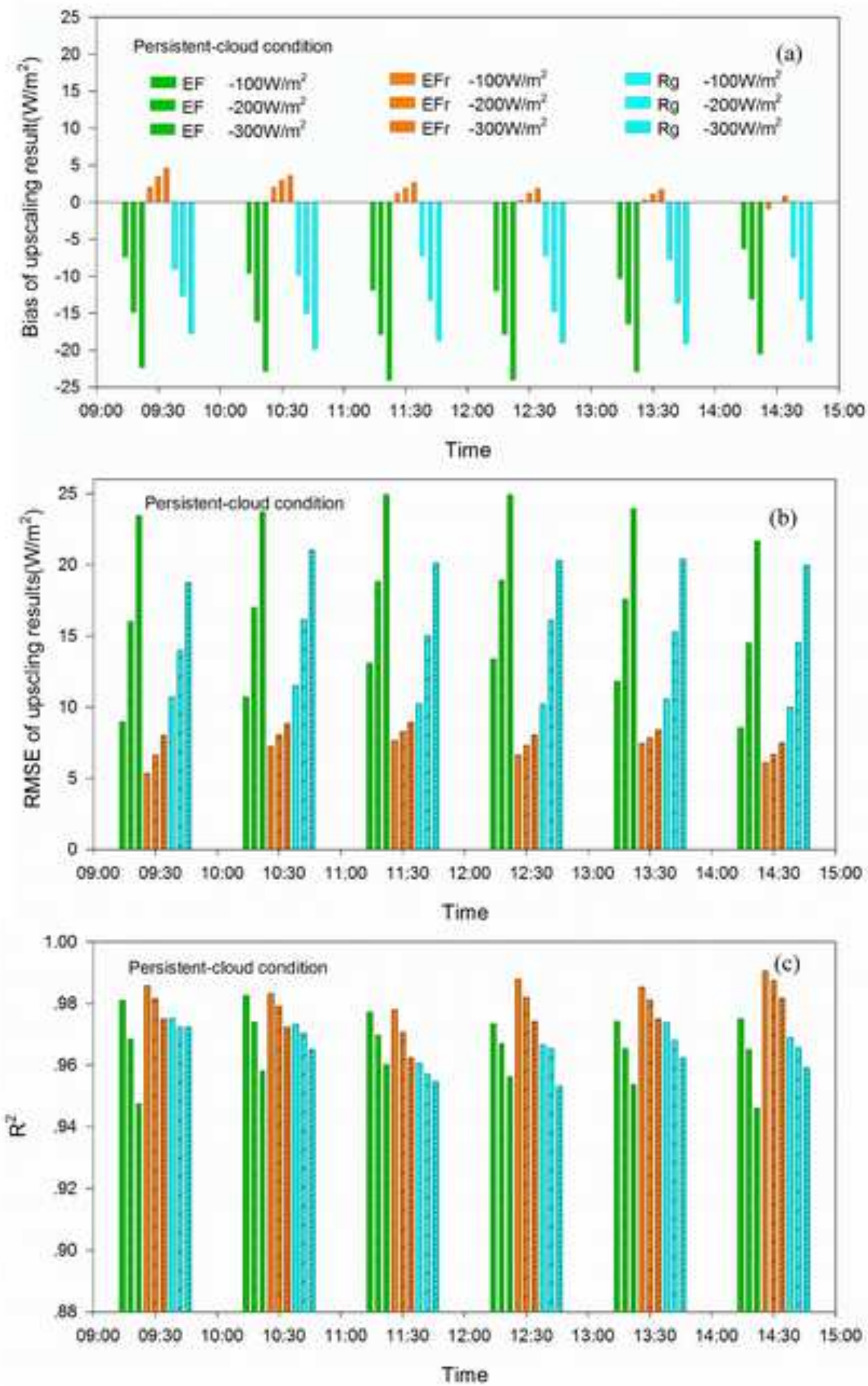
Figure 1. The location of the Yucheng station (red triangle) in China

Figure 2. Comparisons of (a) latent heat flux (LE) (b) sensible heat flux (H) (c) net radiation $\left(R_{n}\right)$ and $(d)$ soil heat flux $(G)$ simulated from ALEX and corresponding in situ measurements

Figure 3. Variations of the upscaling factors $\left(E F, E F_{r}\right.$ and $\left.R_{g}\right)$ from 9:00 to 15:00 in clear days

Figure 4. Statistical measures of the performances of three upscaling methods in converting instantaneous LE to daily value under clear skies

Figure 5. Variations of three upscaling factors $\left(\mathrm{EF}, \mathrm{EF}_{\mathrm{r}}\right.$ and $\mathrm{R}_{\mathrm{g}}$ ) at different upscaling moments when transient cloud appeared before upscaling time

Figure 6. Comparisons of daily LE derived from three methods and simulated daily LE from ALEX at all upscaling moments when transient cloud appeared before upscaling time

Figure 7. Statistical measures of upscaling results by three methods at different upscaling moments when transient cloud appeared before upscaling time (a) Bias, (b) RMSE, (c) $\mathrm{R}^{2}$

Figure 8.Comparisons of daily LE derived by three methods and simulated daily LE from ALEX at all upscaling time when transient cloud appeared after upscaling time Figure 9. Statistical measures of upscaling results from three methods at different upscaling moments when transient cloud appeared after upscaling time (a) Bias, (b) RMSE, (c) $\mathrm{R}^{2}$

Figure 10. Variations of the upscaling factors $\left(\mathrm{EF}, \mathrm{EF}_{\mathrm{r}}\right.$ and $\left.\mathrm{R}_{\mathrm{g}}\right)$ at different upscaling times under persistent-cloud condition

Figure 11. Comparisons of daily LE derived by three methods and daily LE by averaging the simulated values from ALEX in all upscaling times under persistentcloud condition

Figure 12. Statistical measures of upscaling results by three methods at different upscaling moments under persistent-cloud condition (a) Bias, (b) RMSE, (c) $\mathrm{R}^{2}$ 